\title{
Loss Leading as an Exploitative Practice
}

\author{
Zhijun Chen* $\quad$ Patrick Rey ${ }^{\dagger}$
}

December 12, 2011

\begin{abstract}
We show that large retailers, competing with smaller stores that carry a narrower range, can exercise market power by pricing below cost some of the products also offered by the smaller rivals, in order to discriminate multi-stop shoppers from onestop shoppers. Loss leading thus appears as an exploitative device rather than as an exclusionary instrument, although it hurts the smaller rivals as well; banning below-cost pricing increases consumer surplus, rivals' profits, and social welfare. Our insights extend to industries where established firms compete with entrants offering fewer products. They also apply to complementary products such as platforms and applications.
\end{abstract}

JEL Classification: L11, L41

Keywords: loss leading, exploitative practice, market power

*University of Auckland and Ecole Polytechnique. Email: chenzj1219@gmail.com.

†Toulouse School of Economics (UT1C, GREMAQ and IDEI). Email: prey@cict.fr. 


\section{Introduction}

The last three decades have seen the prevalence of large supermarkets, which attract consumers through one-stop shopping. More recently, the retail industry has also featured a substantial increase in concentration - due in part to zoning regulations which, by limiting their internal growth, have encouraged retail chains to merge and to acquire independent stores. As a result, large supermarkets often dominate local retail markets, ${ }^{1}$ in which they mainly compete with much smaller stores. ${ }^{2}$

A key feature of this asymmetric retail competition is that large stores offer a wide range of products, whereas smaller stores focus on narrower product lines on which they can offer better value. Specialist retailers such as wine cellars, fruit and vegetable stores, and traditional bakeries, offer for instance higher quality or more services. Another example is provided by hard discount chains, ${ }^{3}$ which offer limited selections of basic goods, ${ }^{4}$ and moreover rely on private labels and a no-frills approach to minimize operating costs; this low-cost business model allows them to offer prices that are up to $60 \%$ lower than those of leading name brands, and $40 \%$ lower than large retailers' own labels. ${ }^{5}$

While large retailers can exert their market power in various ways ${ }^{6}$ the recent litera-

\footnotetext{
${ }^{1}$ In the UK, where the number of supermarket chains went from 7 to 4 within a few years, the Competition Commission reported that $27 \%$ of larger grocery stores were located in "highly-concentrated local markets", defined as those with three or fewer fascias, including one with more than $60 \%$ of grocery sales within a 10-minute drive-time; see Competition Commission (2008) at pp. 107-108.

${ }^{2}$ In France, where large retailers have stores exceeding 10,000 sq. mt. (up to 24,000+ sq. mt. for Carrefour), zoning regulations have limited the size of new entrants to 300 sq. mt. (now 1,000 sq. mt.).

${ }^{3}$ There are more than 35000 discount stores in Europe, and their share of the grocery market already exceeds 26\% in Germany and $34 \%$ in Norway; the leading hard-discount chains, Aldi and Lidl, operate over 13,000 stores and account for more than $50 \%$ of the discount sales in Europe - see Cleeren et al. (2010) at p. 457. In the U.S., where the hard discount format has emerged more recently, in January 2011 Aldi had already opened more than 1,135 stores (in the name of Trade Joe's or Aldi) in 30 states, and another price-aggressive grocery discounter, Save-A-Lot, operated more than 1,200 stores in 39 states see "Thrifty grocery shoppers head to smaller Save-A-Lot, Aldi", USA Today, 1/25/2011.

${ }^{4}$ According to Steenkamp and Kumar (2009, p.2), hard discouters typically offer 1,000 to 1,500 SKUs, whereas a US supermarket "sells 30,000, on average, and a Wal-Mart supercenter sells 100,000."

${ }^{5}$ See for example Cleeren et al. (2010); Sachon (2010) and Steenkamp and Kumar (2009) also provide detailed accounts of the hard discount retail format.

${ }^{6}$ See Dobson and Waterson (1999) for a detailed discussion.
} 
ture on retail power has mostly focused on buyer power (against suppliers) rather than on seller power (against consumers and smaller rivals). Yet, policy debates suggest that the latter may have the most profound market effects. ${ }^{7}$ One of these debates has centered on loss leading, a practice commonly adopted by large retailers that consists of pricing below cost some of the competitive products (leader products). In the UK, for example, in its first sector inquiry the Competition Commission, noting that "nearly all the main parties sold a small number of products at prices below the cost of purchase", expressed the concern that loss leading "may have a predatory impact on small and specialist retailers" and limit the growth of particular retailers such as hard discounters; yet in its second inquiry it dismissed the concern and argued instead that loss leading "may represent effective competition between retailers and may benefit consumers by reducing the average price for a basket of products". ${ }^{8}$ In Germany, the highest court upheld in 2002 a decision of the Federal Cartel Office enjoining WalMart to stop selling basic food items (such as milk and sugar) below its purchase cost, confirming that a firm "with superior market power in relation to small and medium-sized competitors" should not price below cost. ${ }^{9}$ By contrast, OECD (2007) argues that rules against loss leading are likely to protect inefficient competitors and harm consumers. A similar discrepancy appears in below-cost resale statutes. ${ }^{10}$

In the economic literature, loss leading has been viewed as an advertising strategy adopted to attract consumers who are imperfectly informed of prices; ${ }^{11}$ however, this may

\footnotetext{
${ }^{7}$ See for example the reports of the US Federal Trade Commission $(2001,2003)$, the proceedings of the
} FTC conference held on May 24, 2007, available at http://www.ftc.gov/be/grocery/index.shtm, or the groceries market enquiries of the UK Competition Commission $(2000,2008)$ recommending the adoption of codes of practices. In France, two Acts adopted in 1996 aimed at curbing the expansion of large retailers as well as their market power.

${ }^{8}$ See, respectively, Competition Commission (2000) at p. 131 and p. 132, and (2008) at p. 9.

${ }^{9}$ See http://www.wilmerhale.com/files/Publication/d3382527-7acd-45c6-bae64ef14157e415/Presentation/PublicationAttachment/007af760-21b4-46b0-b356a96612caf3cf/International\%20Competition\%20Law\%20Update12-2-02.pdf

${ }^{10} \mathrm{In}$ the US, 22 states are equipped with general sales-below-cost laws, and 16 additional states prohibit below-cost sales on motor fuel. In the EU, below-cost resale is banned in Belgium, France, Ireland, Luxembourg, Portugal, and Spain, whereas it is generally allowed in the Netherlands and the UK. See Skidmore et al. (2005) and Calvani (2001).

${ }^{11}$ Lal and Matutes (1994), for example, consider a situation where multi-product firms compete for 
be less relevant for routine grocery shopping, where consumers seem to be reasonably aware of prices. ${ }^{12}$ Loss leading has also been interpreted as optimal cross-subsidization by a multi-product monopolist facing different demand elasticities across products; ${ }^{13}$ in practice, however, the choice of leader products appears driven by the competition from smaller stores on specific goods. ${ }^{14}$ Yet little attention has been devoted to the potential adverse effect on smaller rivals and consumers. And while it may be tempting to treat loss leading as predatory pricing, the persistence of below-cost sales over time does not fit well with a scenario in which the predator would recoup the losses incurred during the predation phase by raising the prices afterwards, once rivals have been pushed out of the market.

This paper aims at filling this gap. We develop a model of asymmetric competition between large and small stores. We abstract away from the above-mentioned efficiency justifications by assuming that consumers are perfectly informed of all prices and by allowing for homogeneous consumer valuations for the goods. Our key modelling feature is instead to account for the heterogeneity in consumers' shopping costs: some consumers face higher shopping costs, e.g., because of tighter time constraints or lower taste for consumers who are initially unaware of prices, and find that in equilibrium firms may indeed choose to advertise loss leaders in order to increase store traffic. Ellison (2005) analyzes add-on pricing, and shows that loss leading can be optimal when firms only advertise base goods.

${ }^{12}$ See e.g. Competition Commission (2008), stating at p. 98 that consumers' price comparisons "depend not only on the price of a selection of known-value items (KVIs), but also on the basket price", and that loss leading is "unlikely to mislead consumers in relation to the overall cost of shopping".

${ }^{13}$ Bliss (1988) already views loss leading as a cross-subsidizing strategy, but does not formally establish existence conditions. Beard and Stern (2008) allow for continuous consumer demands and show that loss leading can indeed arise although for rather specific demand functions. Ambrus and Weinstein (2008) study symmetric competition for one-stop shoppers, and show that loss leading can arise only when consumer demand is elastic and exhibits rather specific forms of complementarity.

${ }^{14}$ Loss leaders are mainly staples such as milk and dairy, alcohol, bread and bakery products that consumers purchase repeatedly and regularly - and which constitute the core product lines of small outlets such as hard-discount stores. In its 2000 report, the UK Competition Commission mentions at p. 131 that "we were told that the main cause of negative gross margins was market pressure [...] Asda told us: 'The focus of the discounters on limited lines has enabled them to deliver lower prices and has forced the national retailers to respond. This response primarily has taken the form of the introduction of budget ranges across almost all categories.' Consequently below-cost selling is most obvious on economy lines. [...] This raises the concern that the discounters may be adversely affected by this practice." 
shopping, and thus have a stronger preference for one-stop shopping, whereas others have lower shopping costs and can therefore benefit from multi-stop shopping. ${ }^{15}$

We first present the main insights in a stylized setting where consumers have homogeneous valuations over the range of products offered by a large retailer which, on some of the goods (the competitive segment), faces a fringe of smaller but more efficient rivals. Consumers with low shopping costs then buy the monopolized goods from the large retailer and the competitive goods from the small stores. Consumers with higher shopping costs can choose between buying the full range from the large retailer, or buying only the competitive goods from the smaller rivals. We show that the large retailer adopts a loss leading strategy whenever its broader range allows it to win the competition for these one-stop shoppers: by pricing the competitive goods below cost, and raising the price for the monopolized goods accordingly, the large retailer can maintain the total price charged to one-stop shoppers, while increasing the margin earned on multi-stop shoppers in the monopolized segment. Thus, while the presence of the smaller rivals may generate a competitive pressure, it also allows the large retailer to discriminate consumers according to their shopping costs, and this is best achieved through loss leading - when the comparative advantage conferred by its broader range is large enough, the large retailer can obtain even more profit than in the absence of the smaller rivals.

We then extend the analysis to the case where the large retailer faces a strategic rival rather than a competitive fringe, in which case loss leading also hurts the rival by reducing its market share and squeezing its profit margin. ${ }^{16}$ However, this margin squeeze appears here as a by-product of consumer exploitation rather than driven by exclusionary motives; indeed, it is the very presence of a rival, offering better terms on some products, that allows the large retailer to screen consumers according to their shopping costs. Yet, the lack of exclusionary intent, as well as the fact that the small retailer remains active, should not lead to the conclusion that loss leading is an innocuous strategy, since it hurts both consumers and rivals. We show that a ban on loss leading would discipline the large retailer and benefit consumers as well as the small rival, and would also increase social welfare by improving the distribution efficiency in the competitive segment.

\footnotetext{
${ }^{15}$ Stassen et al. (1999, p. 373) concludes from the US Progressive Grocer Reports (1990-1997) that roughly $75 \%$ of grocery shoppers regularly visit more than one store each week; see also Gijsbrechts et al. (2008).

${ }^{16}$ See for example Dobson (2002).
} 
We also show that loss leading still arises in more general settings with heterogeneous consumer valuations for the goods, product differentiation in the competitive segment, and (imperfect) competition among large retailers. The exploitative use of loss leading thus appears to be a robust feature in market environments where a few large retailers enjoy substantial market power over one-stop shoppers and compete with rivals that focus on narrower product lines, where they benefit from lower costs or better quality.

While this paper has been motivated by loss leading in the retail industry, its insights apply to a variety of situations where: (i) a firm enjoys substantial market power in one market and faces tough competition in other markets; (ii) dealing with a single supplier gives customers some benefits (e.g. due to scale economies, lower adoption or maintenance costs, etc.), which vary across customers. Pricing below cost in the competitive markets then allows the larger firm to screen customers more effectively and extract part of the benefits. This insight can shed a new light on antitrust cases such as $I B M$ and Microsoft; ${ }^{17}$ while the debates mainly focused on exclusionary purposes, our analysis suggests an alternative conceptual framework based instead on exploitation.

This paper can also be related to the literature on bundling and tying (particularly for IT goods which have negligible production costs, where both loss leading and bundling amount to giving the product for free). Part of this literature focuses on the use of (possibly mixed) bundling to enhance price discrimination in monopoly or oligopolistic markets. ${ }^{18}$ Building on this literature, Armstrong and Vickers (2010) consider a symmetric duopoly in which consumers that "mix and match" incur an additional shopping cost; they show that, while prices remain above (or at) cost, mixed bundling tends to raise profit at the expense of consumers. Another part of the literature has focused instead on the use of tying as an entry deterrence device, e.g. by committing to fiercer competition in case of entry or by reducing the value of entering into a single market. ${ }^{19}$ By contrast, here loss leading has little impact on the total price at which large firms offer their bundles, and is not intended to be exclusionary; instead, it primarily increases the price charged on the less competitive segment to those consumers who have lower shopping or adoption costs.

\footnotetext{
${ }^{17}$ See e.g. United States v. International Business Machines Corporation, Docket number 69 Civ. DNE (S.D. NY) and United States of America v. Microsoft Corporation, Civil Action No. 98-1232 TPJ (D.C.).

${ }^{18}$ See e.g. Adams and Yellen (1976) and Matutes and Regibeau (1988).

${ }^{19}$ See e.g. Whinston (1990), Nalebuff (2004), Carlton and Waldman (2002) and Choi and Stefanadis (2001); Rey and Tirole (2007) offer a review of this literature.
} 


\section{Loss leading as an exploitative device}

We present here the main intuition in a stylized setting in which a large retailer $(L)$, supplying a broad range of products, competes with a fringe of smaller retailers $(S)$ that focus on a narrower product line. For the sake of exposition, we simply assume that there are two markets (which can be interpreted as different goods or product lines): $A$ is monopolized by $L$, whereas $B$ can be supplied by $L$ and $S$. Consumers desire at most one unit of $A$ and one unit of $B ;{ }^{20}$ to rule out cross-subsidy motives based on demand elasticity differences as in Bliss (1988), we further assume here that consumers have homogeneous valuations.

Consumers incur a shopping cost $s$ for visiting a store, which reflects the opportunity cost of the time spent in traffic, parking, selecting products, checking out, and so forth; it may also account for the consumer's taste for shopping. Our key modelling feature, reflecting the fact that consumers may be more or less time-constrained, or value their shopping experience in different ways, is that the shopping cost $s$ varies across consumers.

\subsection{A simple example}

A numerical example can illustrate the intuition. Suppose that $L$ can supply $A$ at no cost and $B$ at unit $\operatorname{cost} c=4$, while consumers value $A$ at $u_{A}=10$ and $B$ at $u_{B}=6$. Suppose further that half of the consumers face a high shopping cost $s=4$, whereas the others can shop at no cost. If $L$ were alone, it would supply all consumers at a total price (slightly below) $p^{m}=u_{A}+u_{B}-s=12$, yielding a monopoly profit $\Pi^{m}=12-4=8:^{21}$ $L$ would thus extract all surplus from high-cost consumers but leave the others a surplus of 4 , reflecting the difference in shopping costs.

Suppose now that $B$ is also offered by a competitive fringe $S$ at a price $\hat{p}=2$. $S$ cannot attract high-cost consumers, who would obtain $u_{B}-\hat{p}-s=0 ; L$ can therefore still charge them a total price of $p^{m}$. $L$ could for example price $B$ at cost $\left(p_{B}=4\right)$ and charge the rest on $A\left(p_{A}=8\right): L$ would then sell $A$ only to low-cost consumers (who become "multi-stop shoppers" and buy $B$ from $S$ ) and yet obtain the monopoly margin

\footnotetext{
${ }^{20}$ The assumption of unit demands appears reasonable for groceries and other day-to-day consumer purchases. To be sure, price changes affect the composition of consumer baskets, but are less likely to have a large impact on the volume of purchases for staples.

${ }^{21}$ Selling only to low-cost consumers at a total price $p=16$ yields a lower profit $(16-4) / 2=6<\Pi^{m}$.
} 
on both types of consumers: $p^{m}-c=p_{A}=8$. However, the presence of the small rivals opens a door for screening consumers according to their shopping costs, and this is best achieved by selling $B$ below cost; keeping the total price equal to $p^{m}$, lowering the price for $B$ down to $\hat{p}=2$, and increasing the price for $A$ to $\hat{p}_{A}=10$, does not affect the shopping behavior of high-cost consumers (who still face a total price of $p^{m}$ ), but increases the margin earned on multi-stop shoppers (since $\hat{p}_{A}>p_{A}$ ). This loss-leading strategy thus allows $L$ to charge the monopoly price to one-stop shoppers, and actually extracts here the full value of $A$ from multi-stop shoppers ${ }^{22}$ as a result, it earns a total profit $\Pi=9$, which is greater than in the absence of $S$.

\subsection{Baseline model}

We now consider more general supply and demand conditions, and in particular allow $L$ and $S$ to offer different varieties in the competitive market, $B_{L}$ and $B_{S}$. We denote by $u_{A}, u_{L}$ and $u_{S}$ the consumer valuations for $A, B_{L}$ and $B_{S}$, and by $c_{A}, c_{L}$ and $c_{S}$ the (constant) unit costs. Small retailers supply $B_{S}$ at $\operatorname{cost}\left(p_{S}=c_{S}\right)$, thus offering consumers a value $w_{S} \equiv u_{S}-c_{S}$, and are more efficient than $L$ in this segment (otherwise, $S$ would not sell anything, and multi-stop shopping would never arise): $w_{S}>w_{L} \equiv u_{L}-c_{L}(>0)$; for instance, $S$ can include chained, cost-cutting hard-discounters $\left(c_{S}<c_{L}\right)$, or specialist stores that offer better quality or more service $\left(u_{S}>u_{L}\right)$. $L$ however benefits from its broader range $\left(w_{A} \equiv u_{A}-c_{A}>0\right)$, and may overall offer a higher or lower value: $w_{A L} \equiv w_{A}+w_{L} \gtrless w_{S}$. Finally, we allow for general distributions of the shopping cost $s$, characterized by a cumulative distribution function $F(\cdot)$ and a density function $f(\cdot)$. Intuitively, consumers with a high $s$ favor one-stop shopping, whereas those with a lower $s$ can take advantage of multi-stop shopping; the mix of multi-stop and one-stop shoppers is however endogenous and depends on $L$ 's prices, $p_{A}$ and $p_{L}$.

Let $r_{A L} \equiv p_{A}-c_{A}+p_{L}-c_{L}$ denote $L$ 's total margin and $v_{A L} \equiv u_{A}+u_{L}-p_{A}-p_{L}=$ $w_{A L}-r_{A L}$ denote the consumer value from purchasing $A$ and $B_{L}$. One-stop shoppers prefer $L$ to $S$ ("regime $L$ ") as long as $v_{A L} \geq w_{S}$, and are indeed willing to patronize $L$ as long as $s \leq v_{A L}$; however, consumers favor multi-stop shopping if the additional cost of

\footnotetext{
${ }^{22}$ This is the best $L$ can achieve with low-cost shoppers, who are willing to pay at most $\hat{p}<c$ for $B$.
} 
visiting $S$ is lower than the extra value it offers, which we will denote by $\tau$ :

$$
s \leq \tau \equiv w_{S}-\left(w_{L}-r_{L}\right)
$$

where $r_{L} \equiv p_{L}-c_{L}$ denotes $L$ 's margin on $B_{L}$.

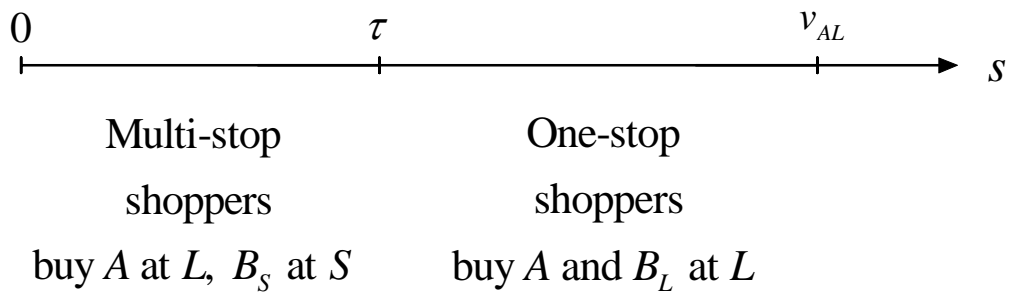

Figure 1: Regime $L$

Thus, in regime $L$ (see Figure 1$){ }^{23} L$ attracts a demand $F\left(v_{A L}\right)-F(\tau)$ for both products (from one-stop shoppers) and an additional demand $F(\tau)$ for product $A$ only (from multistop shoppers); it thus obtains a profit equal to:

$$
r_{A L}\left(F\left(v_{A L}\right)-F(\tau)\right)+r_{A} F(\tau)=r_{A L} F\left(v_{A L}\right)-r_{L} F(\tau)
$$

where $r_{A} \equiv p_{A}-c_{A}=r_{A L}-r_{L}$ denotes $L$ 's margin on $A$. Since $v_{A L}=w_{A L}-r_{A L}$ and $\tau=$ $w_{S}-w_{L}+r_{L}$, this profit expression is additively separable in $r_{A L}$ and $r_{L}$; the optimal pricing policy in regime $L$ thus consists in maximizing $r_{A L} F\left(v_{A L}\right)=r_{A L} F\left(w_{A L}-r_{A L}\right)$ w.r.t. $r_{A L}$, subject to $v_{A L}=w_{A L}-r_{A L} \geq w_{S}$, and minimizing $r_{L} F(\tau)=r_{L} F\left(w_{S}-w_{L}+r_{L}\right)$ w.r.t. $r_{L}$. But the latter obviously leads to $r_{L}<0$, that is, to selling $B_{L}$ below cost.

We thus obtain our first insight:

Lemma 1 It is optimal for $L$ to adopt a loss-leading strategy whenever it chooses to attract one-stop shoppers (regime L).

The intuition is quite simple. Keeping the total margin $r_{A L}$ constant, reducing $r_{L}$ allows $L$ to increase the margin $r_{A}$ it charges on $A$; this does not affect the overall margin on one-stop shoppers (who buy both $A$ and $B$ ), but enhances the margin on multi-stop shoppers (who only buy $A$ ). While the move also transforms some multi-stop shoppers (who initially buy $B_{S}$ from $S$ ) into one-stop shoppers (who now turn to $B_{L}$ ), this, too,

\footnotetext{
${ }^{23}$ Appendix A shows that prices leading to $\tau<0$ (resp., $\tau>v_{A L}$ ) are equivalent to prices yielding $\tau=0$ (resp., $\tau=v_{A L}$ ); therefore, without loss of generality, we can restrict attention to $\tau \in\left[0, v_{A L}\right]$.
} 
benefits $L$ as long as one-stop shoppers are more profitable, that is, as long as $r_{L}>0$. $L$ thus finds it optimal to keep reducing $r_{L}$ until selling $B_{L}$ below cost.

Loss leading thus arises whenever it is optimal for $L$ to attract one-stop shoppers, and the optimal subsidy then balances a favorable impact on $r_{A}$ against an adverse effect on the mix of multi-stop shoppers (who become more profitable than one-stop shoppers when $\left.r_{L}<0\right)$. To characterize further the optimal pricing strategy, in what follows we assume that the inverse hazard rate, $h(\cdot) \equiv F(\cdot) / f(\cdot)$, is strictly increasing. This ensures the quasi-concavity of $L$ 's profit function, and the optimal margin thus satisfies the first-order condition (we only sketch the reasoning here, and provide a formal analysis in Appendix $\mathrm{A})^{24}$

$$
r_{L}^{*}=-h\left(\tau^{*}\right)<0
$$

using $\tau=w_{S}-\left(w_{L}-r_{L}\right)$, the optimal threshold $\tau^{*}$ is characterized by

$$
\tau^{*} \equiv l^{-1}\left(w_{S}-w_{L}\right)>0
$$

where $l(s) \equiv s+h(s)$ is increasing in $s$.

In the absence of any restriction on its total margin $r_{A L}, L$ would maximize the first term, $r_{A L} F\left(v_{A L}\right)$, which is the monopolistic profit that $L$ could earn if $S$ were not present. This profit function is quasi-concave in $r_{A L}$ and the monopoly outcome is thus characterized by the first-order condition:

$$
r_{A L}^{m}=h\left(v_{A L}^{m}\right),
$$

which, using $r_{A L}^{m}=w_{A L}-v_{A L}^{m}$, yields $^{25}$

$$
v_{A L}^{m} \equiv l^{-1}\left(w_{A L}\right)
$$

the associated monopoly profit is $\Pi_{A L}^{m} \equiv r_{A L}^{m} F\left(v_{A L}^{m}\right)$.

\footnotetext{
${ }^{24}$ For the sake of exposition we ignore here non-negativity price constraints. If the comparative advantage of $S$ stems from lower costs, then $w_{S}-w_{L}=c_{L}-c_{S}$ and (2) implies $p_{L}^{*}=c_{L}+r_{L}^{*}=$ $\left(c_{S}+w_{S}-w_{L}\right)-h\left(\tau^{*}\right)>c_{S}+\tau^{*}>0$. However, if the comparative advantage of $S$ comes from a better variety, then it may be optimal for $L$ to offer its own variety for free if the quality difference is large and/or its cost is low.

${ }^{25}$ We implicitly assume away here any relevant upper bound on shopping costs. If $s$ is instead distributed over a range $[0, \bar{s}]$, where $\bar{s} \leq l^{-1}\left(w_{A L}\right)$, then the optimal (monopoly) value is $\bar{v}_{A L}^{m}=\bar{s}$ and the corresponding profit is $w_{A L}-\bar{s}$.
} 
Conversely, this strategy does attract one-stop shoppers as long as $v_{A L}^{m} \geq w_{S}$ (or $\left.w_{A L} \geq l\left(w_{S}\right)\right)$; therefore, when $L$ derives a sufficiently large comparative advantage from its broader product range, the optimal strategy consists of charging the monopoly margin $r_{A L}^{m}$ for the bundle, and $r_{L}^{*}=-h\left(\tau^{*}\right)$ for $B_{L}$. The loss-leading strategy then gives $L$ a profit equal to:

$$
\Pi_{L}^{*}=r_{A L}^{m} F\left(v_{A L}^{m}\right)-r_{L}^{*} F\left(\tau^{*}\right)=\Pi_{A L}^{m}+h\left(\tau^{*}\right) F\left(\tau^{*}\right)
$$

which exceeds the monopoly profit $\Pi_{A L}^{m}$.

That $L$ earns more profit than in the absence of $L$ may at first seem surprising. But when $v_{A L}^{m} \geq w_{S}$, the fringe does not exert any effective competition for one-stop shoppers, and yet allows $L$ to screen multi-stop shoppers from one-stop shoppers. This screening is moreover best achieved by adopting a loss leading strategy: pricing $B_{L}$ below cost allows $L$ to raise the margin $r_{A}$ above $r_{A L}^{m}$, and extract in this way some of the surplus that multi-stop shoppers obtain from the more efficient $S$, while maintaining the monopoly margin $r_{A L}^{m}$ on one-stop shoppers.

When instead $L$ 's comparative advantage is not large enough (namely, $v_{A L}^{m}<w_{S}$ ), $L$ must improve its offer in order to keep attracting one-stop shoppers. It is then optimal for $L$ to match the value offered by the competitive fringe: $\tilde{v}_{A L}^{*}=w_{S}$, or $\tilde{r}_{A L}^{*}=w_{A L}-$ $w_{S}\left(<r_{A L}^{m}\right){ }^{26}$ The loss-leading strategy then gives $L$ a profit equal to:

$$
\tilde{\Pi}_{L}^{*} \equiv\left(w_{A L}-w_{S}\right) F\left(w_{S}\right)+h\left(\tau^{*}\right) F\left(\tau^{*}\right)
$$

Alternatively, $L$ can leave one-stop shoppers to the small retailers ("regime $S$ ") and focus instead on multi-stop shoppers, who are willing to buy $A$ from $L$ as long as the added value $v_{A} \equiv w_{A}-r_{A}$ exceeds the extra shopping cost $s$. In this way, $L$ obtains:

$$
\Pi_{A}^{m} \equiv r_{A}^{m} F\left(v_{A}^{m}\right)=\max _{r_{A}} r_{A} F\left(w_{A}-r_{A}\right)
$$

The loss-leading strategy ${ }^{27}$ is clearly preferable when $v_{A L}^{m} \geq w_{S}$, since it then gives $L$ more profit than the monopolistic level $\Pi_{A L}^{m}$ (which itself exceeds $\Pi_{A}^{m}$ ). As it turns out, it remains preferable as long as $L$ enjoys a comparative advantage over $S$ :

\footnotetext{
${ }^{26}$ If needed, $L$ can slightly enhance its offer to make sure that it attacts all one-stop shoppers.

${ }^{27}$ Throughout the paper, we refer to loss leading as actually selling a product below cost. In regime $S$, $L$ may keep offering $B_{L}$ below cost when $w_{A L}<w_{S}$ (e.g. by charging $r_{L}=-r_{A}^{m}$ ), but only sells $A$.
} 
Proposition 1 Suppose that $L$ faces a competitive fringe of small retailers $(S)$, and that the inverse hazard rate $h(s)$ strictly increases with $s$; then:

- Whenever $L$ enjoys a comparative advantage over $S$ (i.e., $w_{A L}>w_{S}$ ), its unique optimal pricing strategy involves loss leading: $L$ sells the competitive product $B_{L}$ below cost. Furthermore, when its comparative advantage is large (namely, $v_{A L}^{m} \geq$ $\left.w_{S}\right), L$ keeps the total margin for the two products at the monopoly level $\left(r_{A L}=r_{A L}^{m}\right)$ and earns a higher profit than in the absence of any rivals; otherwise L's total margin simply reflects its comparative advantage $\left(r_{A L}=w_{A L}-w_{S}\right)$.

- When instead L faces a comparative disadvantage (i.e., $w_{A L}<w_{S}$ ), its unique optimal pricing strategy consists of monopolizing the non-competitive product and leaving the market of the competitive product to the small retailers.

\section{Proof. See Appendix A.}

Illustration: Uniform density of shopping costs. To illustrate this Proposition, suppose that the shopping cost is uniformly distributed: $F(s)=s$. The monopoly profit, $r_{A L} v_{A L}=$ $r_{A L}\left(w_{A L}-r_{A L}\right)$, is then maximal for $r_{A L}^{m}=v_{A L}^{m}=w_{A L} / 2$. Thus, as long as $w_{A L} \geq 2 w_{S}$, offering the monopoly value suffices to attract one-stop shoppers $\left(v_{A L}^{m} \geq w_{S}\right)$ and $L$ 's profit is given by:

$$
r_{A L}^{m} v_{A L}^{m}-r_{L} \tau=\Pi_{A L}^{m}-r_{L}\left(w_{S}-w_{L}+r_{L}\right)
$$

which is maximal for:

$$
r_{L}^{*}=-\tau^{*}=-\frac{w_{S}-w_{L}}{2}<0 .
$$

In this way, $L$ obtains more than the monopoly profit:

$$
\Pi_{L}^{*}=\Pi_{A L}^{m}-r_{L}^{*} \tau^{*}=\frac{w_{A L}^{2}}{4}+\frac{\left(w_{S}-w_{L}\right)^{2}}{4} .
$$

When instead $2 w_{S}>w_{A L}>w_{S}, L$ maintains the subsidy $r_{L}^{*}$ but can only charge $\tilde{r}_{A L}^{*}=$ $w_{A L}-w_{S}$ to one-stop shoppers; its profit reduces to:

$$
\tilde{\Pi}_{L}^{*}=\left(w_{A L}-w_{S}\right) w_{S}+\frac{\left(w_{S}-w_{L}\right)^{2}}{4}
$$

which coincides with

$$
\Pi_{A}^{m}=\frac{\left(w_{A L}-w_{L}\right)^{2}}{4}
$$


when $w_{A L}=w_{S}$. Finally, whenever $w_{A L}<w_{S}, L$ leaves the competitive segment to its smaller rivals and earns $\Pi_{A}^{m}$ by exploiting its monopoly power on $A$.

Remark: Bundled discounts. In principle, $L$ could offer three prices: one for $A$, one for $B_{L}$ and one for the bundle. But as $L$ sells $A$ to all of its customers, only two prices matter here: the price $p_{A}$ charged for $A$ to multi-stop shoppers, and the total price $p_{A L}$ charged for $A$ and $B_{L}$ to one-stop shoppers; since these prices can equivalently be implemented through stand-alone prices, $p_{A}$ for $A$ and $p_{L} \equiv p_{A L}-p_{A}$ for $B_{L}$, offering an additional bundled discount cannot improve $L$ 's profit here.

Remark: Specialist stores versus hard discounters. As discussed before, two different types of small retail formats may benefit from a comparative advantage in market $B$ : hard discount chains that focus on lower costs (but may offer a similar quality), and specialist stores that offer higher quality (at possibly higher costs). In the latter case, however, consumers may differ in their preferences for quality, and those who do not value quality much may not be interested in multi-stop shopping even if they have low shopping costs. Yet, as shown in Appendix E, loss leading arises as long as some consumers favor quality over price.

Remark: Asymmetric shopping costs. In practice, a consumer may incur different costs when visiting $L$ or $S$ - visiting a larger store may for example be more time-consuming. Our analysis easily extends to such situations. If for example consumers bear a cost $\alpha s$ when patronizing $L$ (and $s$, as before, when visiting $S$ ), the threshold $\tau$ remains unchanged but one-stop shoppers are now willing to patronize $L$ whenever $s<v_{A L} / \alpha$; thus, as long as $L$ attracts one-stop shoppers, its profit is now:

$$
\Pi_{L}=r_{A L} F\left(\frac{v_{A L}}{\alpha}\right)-r_{L} F(\tau)
$$

which leads $L$ to adopt the same loss-leading strategy as before, $r_{L}^{*}=-h\left(\tau^{*}\right)$.

\section{Loss leading and margin squeeze}

Focusing on the case where the small retailer is a competitive fringe allows us to highlight the exploitative effect of loss leading without considering its impact on the smaller rivals, since competition among them dissipates their profits anyway. Yet, in many antitrust cases, small retailers have complained that their margins were squeezed as a result of large retailers' loss-leading strategies. To analyze this margin-squeeze effect, we now 
consider the case where $L$ competes against a single smaller rival $S$, which can thus earn a positive margin $r_{S}>0$ on $B_{S}$.

The previous analysis of $L$ 's pricing behavior still applies, replacing the competitive value $w_{S}$ with the net value offered by $S, v_{S} \equiv w_{S}-r_{S}$. We will focus on the regime where $L$ attracts one-stop shoppers by offering a better value than its rival (regime $L$, where $\left.v_{A L}>v_{S}\right)$. L then faces a demand $F\left(v_{A L}\right)-F(\hat{\tau})$ on both products from one-stop shoppers, and an additional demand $F(\hat{\tau})$ on product $A$ from multi-stop shoppers, where the gain from multi-stop shopping, $\hat{\tau}$, is now given by:

$$
\hat{\tau} \equiv v_{S}-v_{L}=w_{S}-w_{L}+r_{L}-r_{S}
$$

Maximizing its profit, $\Pi_{L}=r_{A L} F\left(v_{A L}\right)-r_{L} F(\hat{\tau})$, leads $L$ to charge again the monopoly margin for the bundle $\left(r_{A L}=r_{A L}^{m}\right)$ and to price the competitive good below cost, with a subsidy satisfying $r_{L}=-h(\hat{\tau})$.

Since $S$ only attracts multi-stop shoppers, it obtains a profit $\Pi_{S}=r_{S} F(\hat{\tau})$ and its best response to $r_{L}$ is thus characterized by the first-order condition:

$$
r_{S}=h(\hat{\tau}) .
$$

The equilibrium margin $\hat{r}_{L}^{*}$ and $\hat{r}_{S}^{*}$ and the resulting threshold $\hat{\tau}^{*}$ thus satisfy:

$$
\hat{\tau}^{*}=w_{S}-w_{L}+\hat{r}_{L}^{*}-\hat{r}_{S}^{*}=w_{S}-w_{L}-2 h\left(\hat{\tau}^{*}\right),
$$

which yields

$$
\hat{\tau}^{*} \equiv j^{-1}\left(w_{S}-w_{L}\right),
$$

where $j(s) \equiv s+2 h(s)$ is strictly increasing. In this candidate equilibrium, $S$ earns a profit

$$
\hat{\Pi}_{S}^{*} \equiv h\left(\hat{\tau}^{*}\right) F\left(\hat{\tau}^{*}\right)
$$

while $L$ obtains

$$
\hat{\Pi}_{L}^{*} \equiv \Pi_{A L}^{m}+h\left(\hat{\tau}^{*}\right) F\left(\hat{\tau}^{*}\right) .
$$

Since $\hat{\tau}^{*}=j^{-1}\left(w_{S}-w_{L}\right)<l^{-1}\left(w_{S}-w_{L}\right)=\tau^{*}$, L's profit is lower than when it was facing a competitive fringe of small retailers. For these margins to form an equilibrium, two conditions must be satisfied: first, $L$ must indeed attract one-stop shoppers; second, $S$ should not benefit from attracting one-stop shoppers, by offering a higher value than $v_{A L}^{m}$ (note that, as $L$ earns more profit than a pure monopolist, it has no incentive to 
exclude $S)$. Both conditions are obviously satisfied when $v_{A L}^{m}>w_{S}\left(\geq v_{S}\right)$. We show in Appendix B that, more generally, they hold when (and only when) $L$ enjoys a significant comparative advantage:

Proposition 2 Suppose that L faces a strategic smaller rival $S$. Then loss leading arises in equilibrium if and only if $w_{A L} \geq \hat{w}_{A L}\left(w_{S}, w_{L}\right)$, where the threshold $\hat{w}_{A L}\left(w_{S}, w_{L}\right)$ lies above $w_{S}$ and increases with $w_{S}$; conversely, in this range there is a unique Nash equilibrium, in which L sells the competitive product below-cost while keeping the total price for both products at the monopoly level, and earns a profit higher than in the absence of the rival.

\section{Proof. See Appendix B.}

Loss leading thus constitutes a robust exploitative device, which allows $L$ to discriminate multi-stop shoppers from one-stop shoppers even when competing with a strategic smaller rival. As before, adopting loss leading allows $L$ to earn even more profit than a pure monopolist if its comparative advantage is large enough. Compared with the case of a competitive fringe, loss leading is now adopted in equilibrium only when it allows $L$ to earn the full monopoly margin from one-stop shoppers, but it does so in a broader range of circumstances: it is shown in Appendix B that the equilibrium condition $w_{A L} \geq \hat{w}_{A L}\left(w_{S}, w_{L}\right)$ is strictly less stringent than the condition $v_{A L}^{m} \geq w_{S}$.

The loss-leading strategy now reduces $S$ 's profit, not only by decreasing its market share, but also by squeezing its margin: $S$ 's best response is $r_{S}=h(\hat{\tau})$, where $\hat{\tau}=$ $l^{-1}\left(w_{S}-w_{L}+r_{L}\right)$ increases with $r_{L}$. Yet, this appears here as a side effect of exploitation rather than as the result of exclusionary motive. In particular, foreclosing the market through strategic tying or (pure) bundling would not be profitable here, since $L$ could obtain at most the monopoly profit in the case of exclusion.

Remark: Strategic margin squeeze. Although margin squeeze appears here as a byproduct of exploitation, the large retailer has an incentive to manipulate its rivals' prices: the lower $S$ 's price for $B_{S}$, the more $L$ can extract from multi-stop shoppers. Thus, if $L$ could move first and act as a Stackelberg leader, it would decrease even further its price for $B_{L}$, so as to force $S$ to respond by decreasing its own price (in contrast with the standard Stackelberg insight, where the leader usually benefits from higher rival prices) and in this way allow $L$ to raise its price on $A$ for multi-stop shoppers. 
However, since $L$ benefits from the presence of $S$, it may also want to tailor its lossleading strategy in order to maintain that presence. Suppose for example that the entry of $S$ is uncertain. It is then profitable for $L$ to adopt a loss-leading strategy in case of entry, in order to extract additional rents from multi-stop shoppers; however, this can reduce the likelihood of entry, in which case $L$ faces a trade-off between exploitation and entry accommodation. We develop a simple model along these lines in Appendix C, which yields the following insights:

Proposition 3 If $L$ and $S$ compete as Stackelberg leader and follower, then in the lossleading equilibrium $L$ prices further below-cost than in the absence of the first-mover advantage. However, if the entry of $S$ depends on the realization of a random entry cost, then L limits instead the subsidy on $B$ so as to increase the likelihood of entry.

\section{Proof. See Appendix C.}

Remark: complementary goods and adoption costs. While we have focused on independent goods, the analysis also applies to the case where $A$ and $B$ are partially substitutable, as well as - even more straightforwardly - to the case where they are complements. Suppose for example that $A$ is a prerequisite for using $B$ (as in the case of CD players and speakers): product $B$ has no value on a stand-alone basis $\left(u_{L}=u_{S}=0\right)$, and must be used together with product $A$ (yielding utilities $u_{A L}$ and $u_{A S}$, where $w_{A S}=u_{A S}-c_{A}-c_{S}>$ $\left.w_{A L}=u_{A L}-c_{A}-c_{L}\right)$. Interpreting $w_{L}$ and $w_{S}$ as $w_{A L}-w_{A}$ and $w_{A S}-w_{A}{ }^{28}$ the above analysis goes through except that, since one-stop shoppers necessarily favor $L$ (since there is no value in patronizing $S$ only), $L$ always engages in loss leading: it charges the monopoly margin $r_{A L}^{m}$ for the bundle and an even greater margin $r_{A L}^{m}+h\left(\tau^{*}\right)$ for $A$ on a stand-alone basis (reflecting the "subsidy" $r_{L}^{*}=-h\left(\tau^{*}\right)$ on $\left.B_{L}\right)$.

Also, while we have focused so far on retail markets, the insights apply to industries in which the costs of adopting a technology, of learning how to use a product, of maintaining equipment, and so forth, play a role similar to the shopping costs that consumers incur to visit an additional store. Indeed, the same analysis goes through, interpreting $s$ as the additional cost that customers must incur in order to use a rival application, rather than that provided by the incumbent. These insights can, therefore, shed a new light on

\footnotetext{
${ }^{28}$ The analysis applies irrespective of whether $A$ generates or not a value on a stand-alone basis, as long as combining it with $B$ generates a higher value.
} 
famous antitrust cases such as the Microsoft saga, in which Microsoft has been accused of excluding rivals in adjacent markets - e.g., the markets for browsers or media players. While the arguments mainly focused there on the rationality of an exclusionary conduct, our analysis suggests an alternative motivation for subsidizing or otherwise encouraging customers to adopt the platform developer's own application, to the detriment of its rivals.

Similar insights also apply to industries in which procuring several categories of products from the same supplier allows a customer to save on operating costs. For example, in its decision blocking the proposed merger between Aerospatiale-Alenia and De Havilland, ${ }^{29}$ the European Commission mentions that the new entity would have benefited from being the only one to offer regional aircraft in all three relevant sizes, thus allowing "one-stop shopper" airlines to save on maintenance and spare parts as well as on pilot training and certification. To see how the analysis can be transposed in such industries, suppose for instance that $L$ covers both segments $A$ and $B$ while $S$ covers $B$ only, and that procuring both products from the same supplier involves a maintenance cost $\lambda$, while dealing with different suppliers increases the maintenance cost to $\lambda+s$, where $s$ is customer-specific. Then, whenever active customers prefer procuring both products (e.g., because the products are complements, or because airlines cannot be viable without operating aircraft in all relevant sizes), the above analysis applies, and $L$ subsidizes again the competitive product (and charges for example the full value for the bundle if $\lambda$ is constant and the goods are complements, or mimics the pricing policy with asymmetric shopping costs if $\lambda$ is proportional to $s$ ).

\section{Banning loss leading}

We now show that loss leading reduces consumer surplus and social welfare as well as smaller rivals' profits. For the sake of exposition, we consider here the scenario where $L$ faces a strategic rival, and focus moreover on the regime in which $L$ attracts one-stop shoppers and thus engages in loss leading (that is, $w_{A L} \geq \hat{w}_{A L}\left(w_{S}, w_{L}\right)$ ).

Suppose $L$ is not allowed to price below cost. We show in Appendix D that $L$ then keeps attracting one-stop shoppers in equilibrium. Since $L$ 's profit function is quasi-

\footnotetext{
${ }^{29}$ See the decision of the European Commission in case No. IV/M053 - Aerospatiale-Alenia/de Havilland (2 October 1991).
} 
concave and separable in $r_{A L}$ and $r_{L}, L$ maintains the total margin at the monopoly level $\left(r_{A L}^{m}\right)$ but now sells $B_{L}$ at cost $\left(r_{L}=0\right)$; consequently, its profit is reduced to $\Pi_{A L}^{m}=r_{A L}^{m} F\left(v_{A L}^{m}\right)$.

Since $L$ no longer subsidizes the competitive segment, $S$ faces more demand: the gain from multi-stop shopping increases from $\tau=w_{S}-w_{L}+r_{L}^{*}-r_{S}$ to $\tau=w_{S}-w_{L}-r_{S}$. Maximizing its profit $\Pi_{S}=r_{S} F(\tau)$ then leads $S$ to charge a margin satisfying $r_{S}=$ $h(\tau)=h\left(w_{S}-w_{L}-r_{S}\right)$, and the equilibrium threshold thus becomes:

$$
\tau^{b}=\tau^{*}=l^{-1}\left(w_{S}-w_{L}\right)>j^{-1}\left(w_{S}-w_{L}\right)=\hat{\tau}^{*}
$$

That is, $S$ increases its market share (from $\hat{\tau}^{*}$ to $\left.\tau^{*}\right)$ as well as its margin (from $\hat{r}_{S}^{*}=h\left(\hat{\tau}^{*}\right)$ to $\left.r_{S}^{b} \equiv h\left(\tau^{*}\right)\right)$ and, consequently, increases its profit by

$$
\Delta_{\Pi_{S}}=h\left(\tau^{*}\right) F\left(\tau^{*}\right)-h\left(\hat{\tau}^{*}\right) F\left(\hat{\tau}^{*}\right)>0 .
$$

Banning loss leading does not affect the value of one-stop shopping, since $L$ maintains the same total margin, $r_{A L}^{m}$. It however encourages consumers to take advantage of multistop shopping: banning loss leading forces $L$ to compete "on the merits", which induces those consumers with a shopping cost lower than $\tau^{*}$ to patronize both stores; in contrast, subsidizing $B_{L}$ (and overcharging $A$ by the same amount) discourages consumers with a shopping cost exceeding $\hat{\tau}^{*}\left(<\tau^{*}\right)$ from visiting $S$. The ban on loss leading thus benefits consumers whose shopping cost lies between $\hat{\tau}^{*}$ and $\tau^{*}$, since the resulting lower price for $A$ allows them to save $\tau^{*}-s$. Using a revealed preference argument, it also benefits genuine multi-stop shoppers (those with a shopping cost $s<\hat{\tau}^{*}$ ), by increasing the value of multi-stop shopping from $\hat{v}_{A S}^{*} \equiv v_{A L}^{m}+\hat{\tau}^{*}$ to $v_{A S}^{*} \equiv v_{A L}^{m}+\tau^{*}$. Overall, a ban on loss leading thus increases total consumer surplus by:

$$
\Delta_{C S}=\left(\tau^{*}-\hat{\tau}^{*}\right) F\left(\hat{\tau}^{*}\right)+\int_{\hat{\tau}^{*}}^{\tau^{*}}\left(\tau^{*}-s\right) d F(s)>0
$$

Finally, fostering multi-stop shopping also enhances efficiency, since more consumers benefit from a better distribution of $B$. The gain in social welfare is equal to:

$$
\Delta_{W}=\int_{\hat{\tau}^{*}}^{\tau^{*}}\left(w_{S}-w_{L}-s\right) d F(s)
$$

and is positive since $\hat{\tau}^{*}<\tau^{*}<w_{S}-w_{L}$. Therefore, we have: 
Proposition 4 Assume that L faces a strategic rival and would engage in loss leading. Banning below-cost pricing then leads to an equilibrium where $L$ maintains the same total margin but sells the competitive good at cost; as a result, the ban increases consumer surplus, the rival's profit, and social welfare.

\section{Proof. See Appendix D.}

A similar analysis applies when $L$ faces a competitive fringe. While loss leading no longer affects rivals' profit, it still reduces their market share and therefore distorts distribution efficiency at the expense of consumers. Banning loss leading thus improves again consumer surplus and social welfare.

As noted in the introduction, competition authorities have been reluctant to treat loss leading as predatory pricing, and some countries have instead adopted below-cost pricing regulations. By showing that loss leading can be used as an exploitative device, to extract extra rents from multi-stop shoppers, rather than as an exclusionary or predatory practice, our analysis sheds a new light on the rationale of loss leading and can thus help placing the assessment of its anticompetitive effects on firmer ground.

\section{Inter-format vs. intra-format competition}

We have so far taken as given the market structure and focused on asymmetric competition between large and small retail formats. We now consider the implications of this analysis for retailers' choice of format. When the founders of Aldi, the Albrecht brothers, took over their family's small neighborhood store in 1946, a retail cooperative was dominating their local market. They took to selling a limited range of private label products, and the success of this innovative approach triggered the development of the hard-discount business model. Later on (in the 1990s), the large supermarket chains began imitating this business model and opened their own hard-discount chains to compete head-to-head with the existing hard discounters. ${ }^{30}$

To capture the key features of these developments, suppose that initially (period 0 ,

\footnotetext{
${ }^{30}$ Carrefour, Casino and Rewer, for example, have already established their own discount chains (namely, ED, Leader Price and Penny); Auchan and Tesco are experimenting along the same lines, whereas Asda, one of the largest retailers in the UK, has acquired the hard discounter Netto. See Steenkamp and Kumar (2009).
} 
say) an incumbent $L$ enjoys a monopoly position for the distribution of two goods, $A$ and $B$. Then in period 1 , one of the potential entrants, $S$, innovates and comes up with a new retail format which, by focusing on a limited product range ( good $B)$, confers a comparative advantage in that product range $\left(w_{S}>w_{L}\right)$, although the product range is so limited that one-stop shoppers will never patronize it $\left(\hat{w}_{A L}\left(w_{S}, w_{L}\right)<w_{A L}\right)$. Finally, in period 2, the incumbent and the other potential entrants can imitate the innovation and open a store with the new format.

Let $\gamma$ denote the fixed cost of opening a small store. In period 1 the innovator will open a small store, even if it anticipates subsequent entry in period 2, as long as $\gamma<$ $\hat{\Pi}_{S}^{*}=\hat{\Delta}^{*} \equiv h\left(\hat{\tau}^{*}\right) F\left(\hat{\tau}^{*}\right)$; note that entry is not only profitable for the innovator, but it also increases $L$ 's profit by the same amount $\hat{\Delta}^{*}$. Consider now period 2 . If the innovator already opened a small store, no other entrant will do so, since head-to-head competition would then eliminate the margin on $B$. $L$ may however benefit from opening its own small store since, while this drives the margins of the small stores down to zero, it allows $L$ to extract more surplus than before from multi-stop shoppers: $\Delta^{*} \equiv h\left(\tau^{*}\right) F\left(\tau^{*}\right)>\hat{\Delta}^{*}$; therefore, $L$ will open its own small store whenever $\gamma<\Delta^{*}-\hat{\Delta}^{*}$.

Alternatively, if mergers were allowed, $L$ could acquire $S$, in which case $L$ and $S$ could together generate a total profit

$$
\begin{aligned}
\Pi_{L}+\Pi_{S} & =r_{A L}\left(F\left(v_{A L}\right)-F(\tau)\right)+\left(r_{S}+r_{A}\right) F(\tau) \\
& =r_{A L} F\left(v_{A L}\right)+\left(r_{S}-r_{L}\right) F(\tau),
\end{aligned}
$$

where the second line is derived by using $r_{A}=r_{A L}-r_{L}$. It is thus optimal to charge $r_{A L}=r_{A L}^{m}$ and $r_{L}-r_{S}=-h\left(\tau^{*}\right)$, where $\tau^{*}=l^{-1}\left(w_{S}-w_{L}\right)$, and in this way $L$ and $S$ generate a joint profit equal to $\Pi_{L}^{*}=\Pi_{A L}^{m}+\Delta^{*}$. So, this scenario yields the same profit as opening a small store competing with $S,{ }^{31}$ but saves the cost $\gamma$ of opening another store. By construction, the profit achieved by the merged entity exceeds the joint profit of $L$ and $S$ in the other scenario; we thus have $\Delta^{*}>2 \hat{\Delta}^{*}$, or $\Delta^{*}-\hat{\Delta}^{*}>\hat{\Delta}^{*}$. Therefore:

Proposition 5 Suppose $\gamma<\hat{\Delta}^{*}\left(<\Delta^{*}-\hat{\Delta}^{*}\right)$. Then:

\footnotetext{
${ }^{31}$ Loss leading however need not arise in case of a merger: while one-stop shoppers face the same total margin $r_{A L}^{m}$ in both scenarios, in the merger case $L$ can not only use $r_{A}$, but also $r_{S}$ to charge a total of $r_{A L}^{m}+\tau^{*}$ to multi-stop shoppers; charging for instance $r_{A}=r_{A L}^{m}, r_{L}=0$ and $r_{S}=w_{S}-w_{L}-\tau^{*}>0$ would do, and would not involve any loss leading.
} 
- S opens a small store when the innovation becomes available in period 1;

- either $L$ merges with $S$, if this is allowed, or opens another small store when the innovation can be imitated in period 2.

Note that we ignored here the possibility for new entrants to open their own large stores. Since head-to-head competition then drives prices down to cost for both goods, this is not interesting on a stand-alone basis. However, if the entrant already operates a small store, opening a large store as well eliminates loss leading, which increases the profit of the small store from $\hat{\Delta}^{*}$ to $\Delta^{*}$. Setting-up the large store in period 1 (that is, at the same time as the small store) moreover prevents the incumbent from opening its own small store in the following period (as this would lead to head-to-head competition for both one-stop and multi-stop shoppers). For this possibility to be attractive, however, the set-up cost of a large store should not exceed $\left(\Delta^{*}-\hat{\Delta}^{*}\right)+\delta \Delta^{*}$, where $\delta$ denotes the discount rate.

Remark: location choices. Our framework can also yield some insights for location choices. For example, suppose that locating the stores closer to each other reduces the additional shopping cost for multi-stop shoppers (so that while one-stop shoppers still face a cost $s$, multi-stop shoppers only incur $(1+\mu) s$, where $\mu<1)$. Our analysis suggests that both firms benefit from such a move, as their profits become, respectively, $\Pi_{L}=$ $r_{A L} F\left(v_{A L}\right)-r_{L} F(\tau / \mu)$ and $\Pi_{S}=r_{S} F(\tau / \mu)$. Accounting for consumers' shopping cost thus creates a motive for reducing the distance between (rival) stores.

Remark: entry in adjacent markets. Similar insights apply to entry decisions in adjacent markets. Suppose for example that firm $L$ initially enjoys a monopoly over some platform $(\operatorname{good} A)$, and that firm $S$ invents a new application $(\operatorname{good} B)$ for that platform. Firm $L$ may then benefit from entering as well in market $B$ - even with a less effective alternative $\left(w_{L}<w_{S}\right)$, not only to increase the value of the platform (by forcing $S$ to offer a better deal on the application, as in Farrell and Katz (2000)), but also to discriminate consumers according to their shopping/adoption costs. Conversely, $S$ may also benefit from entering market $A$, even if this creates head-to-head competition for one-stop shoppers, as it removes $L$ 's incentive to engage in loss leading. 


\section{Robustness}

So far, we used a simple setting in $L$ competes only on specific product segments (market $B$ ) and enjoys a monopoly position in others (market $A$ ); loss leading then allows $L$ to better exploit its market power and charge higher prices to multi-stop shoppers in

the monopolized segments. Furthermore, while we allowed for general distributions of shopping costs, we assumed that consumers' valuations were homogeneous. We describe here several extensions, showing that our insights still apply whenever one-stop shoppers favor the large retailer(s). We first introduce heterogeneity in consumer valuations, which makes the aggregate demand for $A$ or $B$ more sensitive to prices, but may also attenuate the intensity of competition in market $B$ if $L$ and $S$ offer differentiated varieties. We then introduce (imperfect) competition in market $A$.

Introducing heterogeneous valuations in the competitive market does not affect our analysis as long as most one-stop shoppers prefer patronizing $L$, and buy both goods from it, to patronizing $S$ : as before, keeping $r_{A L}$ constant, reducing $r_{L}$ and increasing $r_{A}$ does not affect them, and can only transform some multi-stop shoppers into one-stop shoppers, which benefits $L$ as long as $r_{L}>0$; therefore, in equilibrium $L$ prices $B_{L}$ below cost. To illustrate this, we present in Appendix E a simple setting in which $L$ and $S$ offer differentiated varieties and preferences are distributed in such a way that some consumers may prefer $B_{L}$ to $B_{S}$, while others have the reverse ranking, but one-stop shoppers prefer the bundle $A-B_{L}$ to consuming $B_{S}$ only. This setting applies for example to the case where $S$ (a specialist store, say) offers a better quality; loss leading then arises whenever at least some consumers care sufficiently about quality and engage in multi-stop shopping. The setting also applies to the case of a platform $(A)$ and its applications $\left(B_{L}\right.$ and $\left.B_{S}\right)$.

Introducing heterogeneous valuations for $A$ makes its demand elastic, which limits $L$ 's ability to raise prices in this segment; this may make loss leading less attractive, since its purpose is precisely to earn more from multi-stop shoppers on this segment. Likewise, (imperfect) competition among large retailers curbs their capacity to charge high prices on $A$ and may also discourage the use of loss leading as an exploitative device. To check the robustness of our analysis, we present in Appendix F a variant where consumers are distributed along a Hotelling line: specifically, a consumer located at $x$ obtains a utility $u_{A}-x-p_{A}=w_{A}-r_{A}-x$, where $x$ is distributed according to a cumulative distribution function $G(\cdot)$, with density $g(\cdot)$, so as to allow for a general elastic demand 
function. One-stop shoppers are thus willing to patronize $L$ if $s \leq v_{A L}-x$ or, equivalently, $x \leq x_{A L}(s) \equiv v_{A L}-s$, and prefer this to patronizing $S$ as long as $x \leq \hat{x} \equiv v_{A L}-v_{S}$. As before, consumers prefer multi-stop shopping to patronizing $L$ as long as $s \leq \tau$; however, they now prefer this to patronizing $S$ only if the additional value from consuming $A$ offsets the extra shopping cost:

$$
s \leq v_{A}-x \Longleftrightarrow x \leq x_{A}(s) \equiv v_{A}-s .
$$

Therefore, as long as $L$ attracts some one-stop shoppers $\left(v_{A L}>v_{S}\right)$ and $S$ attracts some multi-stop shoppers $(\tau>0)$, then (see Figure 2):

- consumers with $s<\tau$ buy $A$ from $L$ and $B_{S}$ from $S$ if $x<x_{A}(s)$ (region $D_{A S}$ ), and only $B_{S}$ otherwise (region $\left.D_{S}\right)$;

- consumers with $\tau<s<v_{A L}$ and $x<x_{A L}(s)$ buy both $A$ and $B_{L}$ from $L$ (region $D_{A L}$ ), and otherwise buy either $B_{S}$ only (if $s \leq v_{S}$ ) or nothing (if $s>v_{S}$ ).

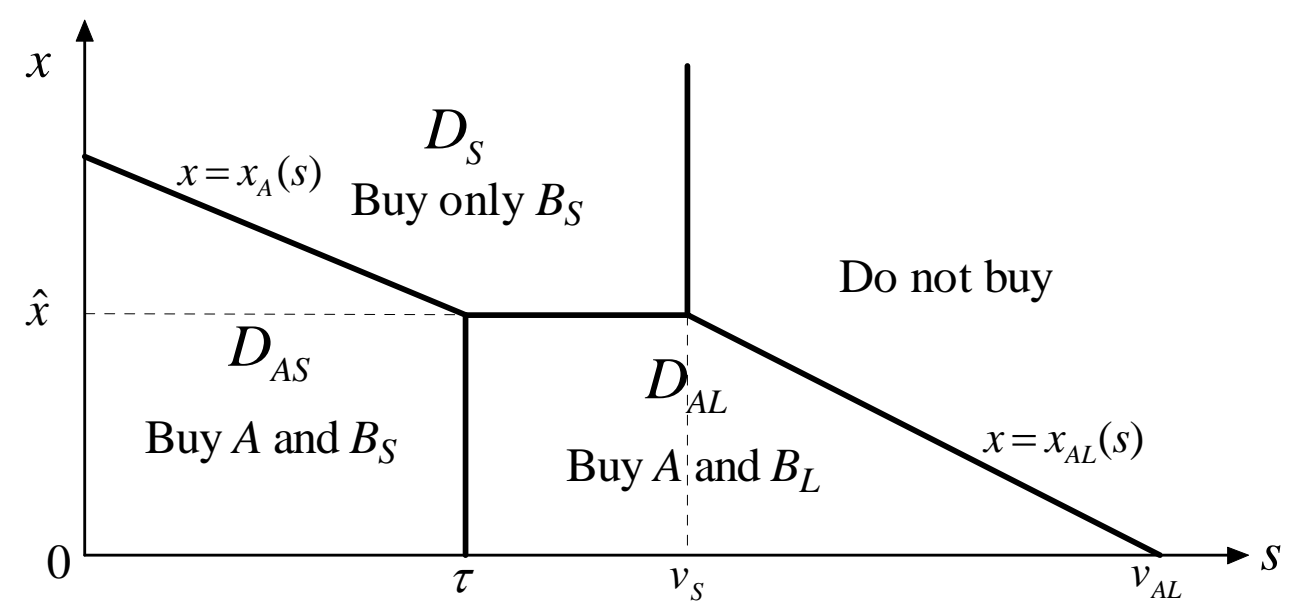

Figure 2: Heterogeneous valuations for $A$

We show that, while the price sensitivity of the demand for $A$ now limits $L^{\prime}$ margins (on $A$ as well as on the assortment $A-B_{L}$ ), $L$ still adopts a loss-leading strategy whenever it attracts (some) one-stop shoppers. As before, pricing $B_{L}$ below cost, and increasing the price of $A$ so as to maintain $r_{A L}$ unchanged, does not affect one-stop shoppers but allows $L$ to extract more surplus from multi-stop shoppers. While this strategy may now induce some consumers to stop buying $A$, the analysis shows that, as long as the inverse hazard rates $h(\cdot)$ and $k(\cdot) \equiv G(\cdot) / g(\cdot)$ are increasing, multi-stop shoppers are actually 
less price-sensitive than one-stop shoppers; ${ }^{32}$ as a result, $L$ aims again at charging greater margins on them, and the loss-leading strategy remains profitable.

Finally, we show that similar insights apply when $L$ competes with another large retailer, $L_{2}$, located at the other end of the Hotelling line. This yields:

Proposition 6 Suppose consumers have heterogeneous valuations for A and/or another large retailer competes à la Hotelling. Then, in any equilibrium in which $L$ attracts some one-stop shoppers, it adopts a loss-leading pricing strategy to extract more surplus from multi-stop shoppers.

Proof. See Appendix F.

\section{Conclusion}

This paper provides a new rationale for the adoption of loss leading and highlights its harmful impact on retail competition and consumers in the absence of efficiency justifications, thus giving support to small rivals' complaints and competition concerns. ${ }^{33}$ It identifies two key drivers: asymmetry in the product range and heterogeneity in consumers' shopping patterns. ${ }^{34}$ The analysis also supports the expressed doubts about the exclusionary motive of the practice, and stresses instead its role as an exploitative device. Yet, this exploitative use of loss leading harms consumers and society as well as the

\footnotetext{
${ }^{32}$ Increasing $r_{A}$ by $d r_{A}$ uniformly decreases marginal consumers' thresholds $x_{A}(s), \hat{x}$ and $x_{A L}(s)$ by $d r_{A}$; the conclusion then follows from the fact that these thresholds are higher for multi-stop shoppers $\left(x_{A}(s)\right)$ than for one-stop shoppers $\left(\hat{x}\right.$ and $\left.x_{A L}(s)\right)$ - see Figure 2.

${ }^{33}$ Chambolle (2005) also studies asymmetric competition between a large retailer and a smaller one, in a different setting in which both retailers are equally efficient, but the majority of consumers are closer to the smaller store, and travel costs are too large for multi-stop shopping; the large retailer then never uses the competitive good as a loss leader, but can instead use in this way the monopolized good, in which case this can benefit consumers as well as society. This is in line with the observation that in practice, concerns are voiced when loss leaders are chosen among the staples offered by the smaller retailers.

${ }^{34}$ We have focused here on consumer shopping costs, which appear as a key factor for routine, repeated purchases. Other dimensions may be relevant for other types of purchases; for example, for less frequent, high value purchases, information and search costs may play a more important role - and customers with lower search costs are again likely to visit more stores. It would be interesting to study whether these alternative sources of underlying heterogeneity yield similar or distinct insights.
} 
smaller rivals, which may provide a rationale for antitrust enforcement. ${ }^{35}$

While the insights are quite robust to variations in cost and demand conditions, policy measures should also take into account potential efficiency justifications, and empirical studies are needed to assess the resulting balance. We have furthermore restricted attention to individual unit demands, which appears reasonable for groceries and other day-to-day purchases, and also assumed away any correlation between consumers' valuations for the goods and their shopping costs; whether our insights apply to market environments where consumers' individual demands are elastic, or underlying characteristics (e.g., wealth) affect both shopping costs and willingness to pay, is left to future research. Likewise, our framework focuses on small retailers that have lower cost or offer better quality, such as hard discounters or specialist stores, but does not account for other categories of small stores, such as convenience stores, that face higher costs (and charge higher prices) but allow consumers to save on shopping costs; we leave to future research the analysis of pricing strategies in such instances.

Finally, while the analysis focuses mainly on retail markets, our insights apply as well to industries where (i) a firm, enjoying substantial market power in one segment, competes with more efficient rivals in other segments, and (ii) procuring these products from the same supplier generates customer-specific benefits. They also apply to complementary products, such as platforms and applications. While some of these industries have hosted heated antitrust cases focusing on predatory pricing or related conduct, our analysis provides an alternative rationale for below-cost pricing based on exploitation rather than exclusion.

\footnotetext{
${ }^{35}$ Allain and Chambolle (2005) and Rey and Vergé (2010) note however that below-cost pricing regulations can allow manufacturers to impose price floors on their retailers, in which case they can be used to better exert market power or to reduce interbrand as well as intrabrand competition; banning loss leaders may then have a perverse effect on consumer welfare.
} 


\section{References}

Adams, William James, and Janet L. Yellen (1976), "Commodity bundling and the burden of monopoly", Quarterly Journal of Economics, 90:47-98.

Allain, Marie-Laure, and Claire Chambolle (2005), "Loss-Leaders Banning Laws as Vertical Restraints", Journal of Agricultural and Food Industrial Organization, 3:1-23.

Ambrus, Attila, and Jonathan Weinstein (2008), "Price Dispersion and Loss Leaders", Theoretical Economics, 3:525-537.

Armstrong, Mark, and John Vickers (2010), "Competitive Non-linear Pricing and Bundling", Review of Economic Studies, 76:1-31.

Beard, Randolph, and Michael Stern (2008), "Continuous Cross Subsidies and Quantity Restrictions", Journal of Industrial Economics, 56:840-861.

Bliss, Christopher (1988), "A Theory of Retail Pricing", Journal of Industrial Economics, 36:375-391.

Calvani, Terry (2001), "Predatory Pricing and State Below-Cost Sales Statutes in the United States: An Analysis", Report for the Competition Bureau, Canada; the report is available at http://www.bureaudelaconcurrence.gc.ca/eic/site/cb-bc.nsf/eng/01292.html.

Carlton, Dennis W., and Michael Waldman (2002), "The Strategic Use of Tying to Preserve and Create Market Power in Evolving Industries", Rand Journal of Economics, 33:194-220.

Chambolle, Claire (2005), "Stratégies de Revente à Perte et Réglementation", Annales d'Economie et de Statistique, 77:59-79.

Choi, Jai Pil, and Christodoulos Stefanadis (2001), "Tying, investment, and the dynamic leverage theory", Rand Journal of Economics, 32(1):52-71.

Cleeren, Kathleen, Frank Verboven, Marnik Dekimpe, and Katrijn Gielens (2010), "Intra- and Inter- Format Competition Among Discounters and Supermarkets", Marketing Science, 29(3):456-473.

Competition Commission, UK (2000), "Supermarkets: A report on the supply of groceries from multiple stores in the United Kingdom", available at http://www.competitioncommission.org.uk/rep_pub/reports/2000/446super.htm

Competition Commission, UK (2008), "Market Investigation into the Supply of Groceries in the UK", available at http://www.competition-commission.org.uk/rep_pub/ reports/2008/538grocery.htm 
Dobson, Paul (2002), "The Economic Effects of Constant Below-Cost Selling Practices by Grocery Retailers", Unpublished report.

Dobson, Paul, and Michael Waterson (1999), "Retailer Power: Recent Developments and Policy Implications." Economic Policy, 28:133-64.

Ellison, Glenn (2005), "A Model of Add-On Pricing", Quarterly Journal of Economics, May:585-637.

Farrell, Joseph, and Michael Katz (2000), "Innovation, Rent Extraction and Integration in Systems Markets", Journal of Industrial Economics 48(4):413-432.

Federal Trade Commission (2001), Report on the FTC Workshop on Slotting Allowances and Other Marketing Practices in the Grocery Industry.

Federal Trade Commission (2003), Slotting Allowances in the Retail Grocery Industry: Selected Case Studies in Five Product Categories.

Gijsbrechts, Els, Katia Campo and Patricia Nisol (2008), "Beyond promotion-based store switching: Antecedents and patterns of systematic multiple-store shopping", International Journal of Research in Marketing, 25:5-21.

Lal, Rajiv, and Carmen Matutes (1994), "Retail Pricing and Advertising Strategies", Journal of Business, 67:345-370.

Matutes, Carmen and Pierre Regibeau (1988), "Mix and Match: Product Compatibility Without Network Externalities", Rand Journal of Economics, 19(2):219-234.

Nalebuff, Barry (2004),"Bundling as an Entry Barrier", Quarterly Journal of Economics, Vol. 119: 159-188

OECD (2007), "Resale Below Cost Laws and Regulations", OECD Journal of Competition Law and Policy, 9:169-255.

Rey, Patrick, and Jean Tirole (2007), "A Primer on Foreclosure", in Handbook of Industrial Organization III.

Rey, Patrick, and Thibaud Vergé (2010), "Resale Price Maintenance and Interlocking Relationships", The Journal of Industrial Economics, 58(4):928-961.

Sachon, Marc (2010), "The Hard Discount Model in Retailing", Consultant Report in IESE Business School.

Skidmore, Mark, James Peltier and James Alm (2005), "Do State Motor Fuel SalesBelow-Cost Laws Lower Prices?", Journal of Urban Economics, 57:189-211.

Stassen, Robert E., John D. Mittelstaedt and Robert A.Mittelstaedt (1999), "Assort- 
ment overlap: Its effect on shopping patterns in a retail market when the distributions of prices and goods are known", Journal of Retailing, 75(3):371-386.

Steenkamp, Jan-Benedict E. M., and Nirmalya Kumar (2009), "Don’t Be Undersold", Harvard Business Review, December 2009.

Whinston, Michael (1990), "Tying, Foreclosure, and Exclusion", American Economic Review, Volume 80:837-859. 


\section{Online Appendix Not for publication}

\section{A Proof of Proposition 1}

Suppose first that $v_{A L} \geq w_{S}$, that is, $r_{A L} \leq w_{A L}-w_{S}$ ("regime $L^{\prime \prime}$ ). We first show that, without loss of generality, we can focus on prices such that $\tau \in\left[0, v_{A L}\right]$. If $\tau>v_{A L}$ (i.e., $w_{S}-w_{L}+r_{L}>w_{A L}-r_{A L}$, or $\left.r_{L}>r_{L}^{\prime} \equiv\left(w_{A L}-r_{A}-\left(w_{S}-w_{L}\right)\right) / 2\right)$, there are no one-stop shoppers: active consumers buy $A$ from $L$ and $B_{S}$ from $S$, and do so as long as $2 s<v_{A}+w_{S}$; however, keeping $r_{A}$ constant, decreasing $r_{L}$ to $r_{L}^{\prime}$ such that $\tau^{\prime}=v_{A L}^{\prime}$ does not affect the number of active consumers (since $v_{A}$ does not change), who still visit both stores as before. If instead $\tau<0$ (i.e., $r_{L}<-w_{S}-w_{L}$ ), there are no multi-stop shoppers: active consumers only visit $L$, and do so as long as $s<v_{A L}=w_{A L}-r_{A L}$; however, keeping $r_{A L}$ constant, increasing $r_{L}$ to $r_{L}^{\prime}=-\left(w_{S}-w_{L}\right)$ yields $\tau^{\prime}=0$ without affecting consumer behavior. The condition $\tau \geq 0$ moreover ensures that prospective multi-stop shoppers are indeed willing to buy $A$ on a stand-alone basis: $w_{S} \leq v_{A L}=w_{A L}-r_{A}-r_{L}$ implies $r_{A} \leq w_{A L}-w_{S}-r_{L}=w_{A L}-w_{L}-\tau<w_{A}$.

Thus, consumers whose shopping cost lies in $[0, \tau]$ buy $A$ from $L$ (and $B_{S}$ from $S$ ), whereas those with a shopping cost in $\left[\tau, v_{A L}\right]$ buy both $A$ and $B_{L}$ from $L$. Using $v_{A L}=$ $w_{A L}-r_{A L}$ and $\tau=w_{S}-w_{L}+r_{L}, L$ 's optimization program within regime $L$ can thus be expressed as:

$$
\begin{aligned}
\max _{r_{A L}, r_{L}} \Pi_{L}\left(r_{A L}, r_{L}\right)= & r_{A L} F\left(w_{A L}-r_{A L}\right)-r_{L} F\left(w_{S}-w_{L}+r_{L}\right), \\
& \text { subject to } r_{A L} \leq w_{A L}-w_{S}
\end{aligned}
$$

where $\Pi_{L}\left(r_{A L}, r_{L}\right)$ is additively separable and moreover strictly quasi-concave ${ }^{36}$ in $r_{A L}$ and $r_{L}$. L's optimization program can thus be decomposed into:

$$
\begin{aligned}
& \max _{r_{A L}} r_{A L} F\left(w_{A L}-r_{A L}\right), \\
& \text { s. t. } r_{A L} \leq w_{A L}-w_{S}
\end{aligned}
$$

which leads to $r_{A L}=\min \left\{r_{A L}^{m}, w_{A L}-w_{S}\right\}$ and $v_{A L}=\max \left\{v_{A L}^{m}, w_{S}\right\}$, and

$$
\min _{r_{L}} r_{L} F\left(w_{S}-w_{L}+r_{L}\right)
$$

\footnotetext{
${ }^{36}$ The derivative w.r.t. $r_{A L}$ is of the form $f\left(w_{A L}-r_{A L}\right) \phi\left(r_{A L}\right)$, where $\phi\left(r_{A L}\right) \equiv h\left(w_{A L}-r_{A L}\right)-r_{A L}$ is strictly decreasing. A similar reasoning applies below to the other profit functions of $L$ and $S$.
} 
which yields the first-order condition:

$$
r_{L}^{*}=-h\left(w_{S}-w_{L}+r_{L}^{*}\right)=-h\left(\tau^{*}\right)<0
$$

Using $r_{L}^{*}=\tau^{*}-\left(w_{S}-w_{L}\right)=-h\left(\tau^{*}\right)$, the optimal threshold $\tau^{*}$ is given by:

$$
\tau^{*} \equiv l^{-1}\left(w_{S}-w_{L}\right)>0
$$

Note that this threshold satisfies $\tau^{*}<v_{A L}^{m}$. To see this, take instead $v_{A L}$ and $\tau$ as control variables and rewrite $L$ 's profit as:

$$
\begin{aligned}
\Pi_{L}\left(v_{A L}, \tau\right) & =r_{A L} F\left(v_{A L}\right)-r_{L} F(\tau) \\
& =\left(w_{A L}-v_{A L}\right) F\left(v_{A L}\right)+\left(w_{S}-w_{L}-\tau\right) F(\tau) .
\end{aligned}
$$

Then we have $v_{A L}^{m}=\arg \max _{v}\left(w_{A L}-v\right) F(v)>\arg \max _{v}\left(w_{S}-w_{L}-v\right) F(v)=\tau^{*}$, since $w_{A L} \geq l\left(w_{S}\right)\left(>w_{S} \geq w_{S}-w_{L}\right)$.

Suppose now that $v_{A L}<w_{S}$, that is, $r_{A L}>w_{A L}-w_{S}$ ("regime $S "$ ). $L$ then only attracts multi-stop shoppers, who buy $A$ from it as long as $s \leq v_{A}=w_{A}-r_{A}$. $L$ thus obtains:

$$
\Pi_{L}=r_{A} F\left(v_{A}\right)=r_{A} F\left(w_{A}-r_{A}\right),
$$

which is maximal for $r_{A}^{m}$ and $v_{A}^{m}=w_{A}-r_{A}^{m}$, characterized by:

$$
r_{A}^{m}=h\left(v_{A}^{m}\right), v_{A}^{m}=l^{-1}\left(w_{A}\right)
$$

$L$ 's profit in regime $S$ is thus at most:

$$
\Pi_{A}^{m} \equiv r_{A}^{m} F\left(v_{A}^{m}\right)
$$

As already noted, regime $L$ is clearly preferable when $v_{A L}^{m} \geq w_{S}$, since it then gives $L$ more profit than the monopolistic level $\Pi_{A L}^{m}$, which itself is greater than $\Pi_{A}^{m}$ :

$$
\Pi_{A L}^{m}=\max _{r} r F\left(w_{A L}-r\right)>\max _{r} r F\left(w_{A}-r\right)=\Pi_{A}^{m},
$$

since $w_{A L}>w_{A}$. We now show that regime $L$, and the associated loss-leading strategy, remains profitable when $w_{A L} \geq w_{S}>v_{A L}^{m}$, where it involves $r_{L}^{*}<0$ and $\tilde{r}_{A L}^{*}=w_{A L}-w_{S}$. To see this, fixing $\tilde{r}_{A L}^{*}$ and using $r_{A}$ rather than $r_{L}$ as the optimization variable, the margin on $B_{L}$ and the shopping cost threshold can be expressed as:

$$
r_{L}=\tilde{r}_{A L}^{*}-r_{A}=w_{A L}-w_{S}-r_{A}, \tau=w_{S}-w_{L}+r_{L}=w_{A L}-w_{L}-r_{A}=w_{A}-r_{A} .
$$


The maximum profit achieved in regime $L, \tilde{\Pi}_{L}^{*}$, can then be written as:

$$
\begin{aligned}
\tilde{\Pi}_{L}^{*} & =\tilde{r}_{A L}^{*}\left(F\left(\tilde{v}_{A L}^{*}\right)-F\left(\tau^{*}\right)\right)+r_{A}^{*} F\left(\tau^{*}\right) \\
& =\left(w_{A L}-w_{S}\right)\left(F\left(w_{S}\right)-F\left(\tau^{*}\right)\right)+r_{A}^{*} F\left(\tau^{*}\right) \\
& =\max _{r_{A}}\left\{\left(w_{A L}-w_{S}\right)\left(F\left(w_{S}\right)-F\left(w_{A}-r_{A}\right)\right)+r_{A} F\left(w_{A}-r_{A}\right)\right\} \\
& \geq\left(w_{A L}-w_{S}\right)\left(F\left(w_{S}\right)-F\left(w_{A}-r_{A}^{m}\right)\right)+r_{A}^{m} F\left(w_{A}-r_{A}^{m}\right) \\
& =\left(w_{A L}-w_{S}\right)\left(F\left(w_{S}\right)-F\left(v_{A}^{m}\right)\right)+\Pi_{A}^{m} .
\end{aligned}
$$

Since $w_{S}>v_{A L}^{m}=l^{-1}\left(w_{A L}\right)>l^{-1}\left(w_{A}\right)=v_{A}^{m}, \tilde{\Pi}_{L}^{*} \geq \Pi_{A}^{m}$ whenever $w_{A L} \geq w_{S}$.

Conversely, when $w_{A L}<w_{S}$, then $L$ can indeed achieve $\Pi_{A}^{m}$ in regime $S$ (e.g., $r_{L}=0$ and $r_{A}=r_{A}^{m}$ satisfy $r_{A L}=r_{A}^{m}>0>w_{A L}-w_{S}$, and thus $\left.v_{A L}<w_{S}\right)$, and we have:

$$
\begin{aligned}
\tilde{\Pi}_{L}^{*} & =\left(w_{A L}-w_{S}\right)\left(F\left(w_{S}\right)-F\left(w_{A}-\tilde{r}_{A}^{*}\right)\right)+\tilde{r}_{A}^{*} F\left(w_{A}-\tilde{r}_{A}^{*}\right) \\
& <\tilde{r}_{A}^{*} F\left(w_{A}-\tilde{r}_{A}^{*}\right) \\
& \leq \Pi_{A}^{m},
\end{aligned}
$$

where the first inequality stems from $w_{S}>w_{A L}\left(>w_{A}-\tilde{r}_{A}^{*}\right)$.

Finally, in the limit case where $w_{A L}=w_{S}$, using $B_{L}$ as a loss leader amounts to monopolizing product $A$. Offering $v_{A L}=w_{S}$ requires $r_{A L}=w_{A L}-v_{A L}=0$, or $r_{A}=-r_{L}$, and the optimal subsidy thus maximizes $-r_{L} F(\tau)=-r_{L} F\left(w_{S}-w_{L}+r_{L}\right)=r_{A} F\left(w_{A}-r_{A}\right)$. Therefore, in both cases $L$ obtains (from multi-stop shoppers) the monopoly margin on $A$, and makes no profit (from one-stop shoppers) on the bundle $A-B_{L}$ (since either it charges them $r_{A L}=0$, or they go to $S$ ). Finally, while the loss-leading strategy may yield a lower price for $B_{L}$ (in the monopolization scenario, $L$ may actually stop carrying $B_{L}$ ), this does not affect multi-stop shoppers (who do not buy $B_{L}$ from $L$ ), whereas one-stop shoppers are indifferent between buying $A$ and $B_{L}$ from $L$ or $B_{S}$ only from $S$.

\section{B Proof of Proposition 2}

We derive here the conditions under which the loss leading outcome $\left(\hat{r}_{A L}^{*}=r_{A L}^{m}\right.$ and $\hat{r}_{L}^{*}=$ $-\hat{r}_{S}^{*}=-h\left(\hat{\tau}^{*}\right)$, where $\left.\hat{\tau}^{*}=j^{-1}\left(w_{S}-w_{L}\right)\right)$ forms a Nash equilibrium, before checking the uniqueness of the equilibrium. To attract one-stop shoppers, $L$ must offer a better value 
than $S: 37$

$$
v_{A L}^{m} \geq \hat{v}_{S}^{*} \equiv w_{S}-h\left(\hat{\tau}^{*}\right) .
$$

This condition implies $v_{A L}^{m} \geq \hat{v}_{S}^{*}>\hat{v}_{S}^{*}-\hat{v}_{L}^{*}=\hat{\tau}^{*}$, which in turn implies $w_{A L}>w_{S}$ :

$$
w_{A L}=l\left(v_{A L}^{m}\right) \geq l\left(\hat{v}_{S}^{*}\right)=\hat{v}_{S}^{*}+h\left(\hat{v}_{S}^{*}\right)=w_{S}-h\left(\hat{\tau}^{*}\right)+h\left(\hat{v}_{S}^{*}\right)>w_{S} .
$$

Moreover, while $L$ has no incentive to exclude its rival, since it earns more profit than a pure monopolist, $S$ may want to attract one-stop shoppers by reducing $r_{S}$ so as to offer $v_{S} \geq v_{A L}^{m}$. Such a deviation allows $S$ to attract all consumers (one-stop or multi-stop shoppers) with shopping costs $s \leq v_{S}$ and thus yields a profit $\Pi_{S}^{d}\left(v_{S}\right) \equiv$ $r_{S} F\left(v_{S}\right)=\left(w_{S}-v_{S}\right) F\left(v_{S}\right)$. A simple revealed argument yields $\arg \max _{v} \Pi_{S}^{d}(v) \leq v_{A L}^{m} \equiv$ $\arg \max _{v}\left(w_{A L}-v\right) F(v)$, since $w_{S}<w_{A L}$; as $\Pi_{S}^{d}\left(v_{S}\right)$ is quasi-concave in $v_{S}$, increasing $v_{S}$ further above $v_{A L}^{m}$ would thus reduce $S$ 's profit. It is therefore optimal for $S$ to offer precisely $v_{S}^{d}=v_{A L}^{m}$ (or slightly above $v_{A L}^{m}$, if one-stop shoppers are indifferent between the two stores in this case), which gives $S$ a profit equal to $\Pi_{S}^{d}\left(v_{A L}^{m}\right)=\left(w_{S}-v_{A L}^{m}\right) F\left(v_{A L}^{m}\right)$. The loss-leading outcome is immune to such a deviation if and only if

$$
\hat{\Pi}_{S}^{*} \equiv h\left(\hat{\tau}^{*}\right) F\left(\hat{\tau}^{*}\right) \geq \hat{\Pi}_{S}^{d} \equiv\left(w_{S}-v_{A L}^{m}\right) F\left(v_{A L}^{m}\right) .
$$

This condition can be further written as:

$$
\Psi\left(w_{A L} ; w_{S}\right) \equiv\left(w_{S}-v_{A L}^{m}\right) F\left(v_{A L}^{m}\right) \leq \hat{\Pi}_{S}^{*},
$$

where $v_{A L}^{m}=l^{-1}\left(w_{A L}\right)$ and thus satisfies $v_{A L}^{m}+h\left(v_{A L}^{m}\right)=w_{A L}$. Therefore:

$$
\begin{aligned}
\frac{\partial \Psi}{\partial w_{A L}}\left(w_{A L} ; w_{S}\right) & =\left(\left(w_{S}-v_{A L}^{m}\right) f\left(v_{A L}^{m}\right)-F\left(v_{A L}^{m}\right)\right) \frac{d v_{A L}^{m}}{d w_{A L}} \\
& =\left(w_{S}-v_{A L}^{m}-h\left(v_{A L}^{m}\right)\right) \frac{f\left(v_{A L}^{m}\right)}{1+h^{\prime}\left(v_{A L}^{m}\right)} \\
& =\left(w_{S}-w_{A L}\right) \frac{f\left(v_{A L}^{m}\right)}{1+h^{\prime}\left(v_{A L}^{m}\right)} .
\end{aligned}
$$

It follows that, in the range $w_{A L} \geq w_{S}, \Psi\left(w_{A L} ; w_{S}\right)$ decreases with $w_{A L}$ (and strictly so for $\left.w_{A L}>w_{S}\right)$. Thus, condition (11) amounts to $w_{A L} \geq \hat{w}_{A L}\left(w_{S}, w_{L}\right)$, where $\hat{w}_{A L}\left(w_{S}, w_{L}\right)$ is the unique solution to $\Psi\left(w_{A L} ; w_{S}\right)=\hat{\Pi}_{S}^{*}$. To show that this solution exists and

\footnotetext{
${ }^{37}$ As before, this is equivalent to $w_{A L}-w_{L}-\hat{r}_{A}^{*}=v_{A L}^{m}-\hat{v}_{L}^{*} \geq \hat{v}_{S}^{*}-\hat{v}_{L}^{*}=\hat{\tau}^{*}(>0)$, which implies that multi-stop shoppers are indeed willing to buy $A$ when visiting $L$. Moreover, this condition also implies $v_{A L}^{m}>\hat{v}_{S}^{*}-\hat{v}_{L}^{*}=\hat{\tau}^{*}(>0)$.
} 
lies above $w_{S}$, note first that $\Psi$ becomes negative for $w_{A L}>l\left(w_{S}\right)$ (since then $v_{A L}^{m}=$ $\left.l^{-1}\left(w_{A L}\right)>w_{S}\right)$, and that for $w_{A L}=w_{S}, \Psi\left(w_{A L} ; w_{S}\right)=\left(w_{A L}-v_{A L}^{m}\right) F\left(v_{A L}^{m}\right)=\Pi_{A L}^{m}=$ $\max _{v}\left(w_{A L}-v\right) F(v)$; since $w_{A L}>w_{S}-w_{L}+\hat{r}_{L}^{*}$, this exceeds $\hat{\Pi}_{S}^{*}=\max _{\tau}\left(w_{S}-w_{L}+\hat{r}_{L}^{*}-\tau\right) F(\tau)$.

Finally, in the range $w_{A L}>w_{S}\left(>w_{S}-\hat{v}_{L}^{*}\right)$, a simple revealed argument yields:

$$
\hat{\tau}^{*}=\arg \max _{v}\left(w_{S}-\hat{v}_{L}^{*}-\tau\right) F(\tau)<v_{A L}^{m}=\arg \max _{v}\left(w_{A L}-v\right) F(v) .
$$

Therefore, (11), which is equivalent to:

$$
v_{A L}^{m} \geq w_{S}-\frac{h\left(\hat{\tau}^{*}\right) F\left(\hat{\tau}^{*}\right)}{F\left(v_{A L}^{m}\right)},
$$

implies (10). The two conditions (10) and (11) thus boil down to $w_{A L} \geq \hat{w}_{A L}\left(w_{S}, w_{L}\right)$.

It remains to show that $\hat{w}_{A L}\left(w_{S}, w_{L}\right)$ increases with $w_{S}$. Differentiating $\hat{w}_{A L}\left(w_{S}, w_{L}\right)$ with respect to $w_{S}$ yields:

$$
\frac{\partial \hat{w}_{A L}}{\partial w_{S}}=\frac{\frac{\partial \Psi}{\partial w_{S}}-\frac{\partial \hat{\Pi}_{S}^{*}}{\partial w_{S}}}{-\frac{\partial \Psi}{\partial w_{A L}}},
$$

where the denominator is positive in the relevant range, whereas the numerator is equal to:

$$
\begin{aligned}
\frac{\partial \Psi}{\partial w_{S}}-\frac{\partial \hat{\Pi}_{S}^{*}}{\partial w_{S}} & =F\left(v_{A L}^{m}\right)-\frac{d\left(h\left(\hat{\tau}^{*}\right) F\left(\hat{\tau}^{*}\right)\right)}{d \hat{\tau}^{*}} \frac{\partial \hat{\tau}^{*}}{\partial w_{S}} \\
& =F\left(v_{A L}^{m}\right)-\frac{1+h^{\prime}\left(\hat{\tau}^{*}\right)}{1+2 h^{\prime}\left(\hat{\tau}^{*}\right)} F\left(\hat{\tau}^{*}\right)
\end{aligned}
$$

which is positive since $v_{A L}^{m}>\hat{\tau}^{*}$.

We now show that no other equilibrium exists when $w_{A L} \geq \hat{w}_{A L}\left(w_{S}, w_{L}\right)$. First, we turn to regime $S$, in which one-stop shoppers patronize $S\left(v_{A L}<v_{S}\right)$, and show that there is no such equilibrium when $w_{A L}>w_{S}$. In this regime, $L$ faces only a demand $F\left(v_{A}\right)$ for $A$ from multi-stop shoppers, where $v_{A}=w_{A}-r_{A}$, and thus makes a profit equal to $r_{A} F\left(v_{A}\right) . L$ could however deviate and attract one-stop shoppers by reducing $r_{L}$ (keeping $r_{A}$ and thus $v_{A}$ constant) so as to offer $v_{A L}^{\prime}=v_{S}$ (or slightly above $v_{S}$ ). Doing so would not change the number of multi-stop shoppers, since $\tau^{\prime}=v_{S}-v_{L}^{\prime}=v_{A L}^{\prime}-v_{L}^{\prime}=v_{A}^{\prime}=v_{A}$, and $L$ would obtain the same margin, $r_{A}$, from those consumers. But it would now attract one-stop shoppers (those for which $v_{A} \leq s \leq v_{A L}=v_{S}$ ), from which $L$ could earn a total margin $r_{A L}^{\prime}=w_{A L}-v_{A L}^{\prime}=w_{A L}-v_{S}=w_{A L}-w_{S}+r_{S}$. Since any candidate equilibrium requires $r_{S} \geq 0$, the deviation would be profitable when $w_{A L}>w_{S}$.

Second, consider the boundary between the two regimes, in which one-stop shoppers are indifferent between visiting $L$ or $S\left(v_{A L}=v_{S}\right)$. Note that there must exist some 
active consumers, since either retailer can profitably attract consumers by charging a small positive margin; therefore, we must have $v_{A L}=v_{S}>0$. Suppose that all active consumers are multi-stop shoppers (in which case $L$ only sells $A$ while $S$ sells $B_{S}$ to all consumers), which requires $v_{A L}=v_{S} \leq \tau$. Applying the same logic as in the beginning of Appendix A, we can without loss of generality focus on the case $v_{A L}=v_{S}=\tau$. It is then profitable for $L$ to transform some multi-stop shoppers into one-stop shoppers, by reducing its margin on $B_{L}$ to $r_{L}^{\prime}=w_{L}-\varepsilon>0$ and increasing $r_{A}$ by $\varepsilon$, so as to keep $v_{A L}$ constant: doing so does not affect the total number of active consumers, but transforms those whose shopping cost lies between $\tau^{\prime}=v_{S}-v_{L}^{\prime}=\tau-\varepsilon$ and $\tau$ into one-stop shoppers. While $L$ obtains the same margin on them (since $r_{A L}^{\prime}=r_{A L}$ ), it now obtains a higher margin $r_{A}^{\prime}>r_{A}$ on the remaining multi-stop shoppers.

Therefore, some consumers must visit a single store, and by assumption must be indifferent between visiting either store $\left(v_{A L}=v_{S}\right)$. Suppose now some one-stop shoppers visit $S$. Since $S$ can avoid making losses, we must then have $r_{S} \geq 0$. But then, $v_{A L}=v_{S}$ implies $r_{A L}=r_{S}+w_{A L}-w_{S}>0$ and, thus, it would be profitable for $L$ to reduce $r_{A L}$ slightly, so as to attract all one-stop shoppers. Therefore, all one-stop shoppers must go to $L$ if $r_{A L}>0$. Conversely, we must have $r_{S} \leq 0$, otherwise $S$ would benefit from slightly reducing its margin so as to attract all one-stop shoppers. Therefore, in any candidate equilibrium such that $v_{A L}=v_{S}>0$, either:

- There are some multi-stop shoppers (i.e. $\tau>0$ ) and thus $r_{S}=0$; but then, slightly increasing $r_{S}$ would allow $S$ to keep attracting some multi-stop shoppers and obtain a positive profit, a contradiction.

- Or, all consumers buy both products from $L$, which requires $r_{L} \leq r_{S}-\left(w_{S}-w_{L}\right) \leq$ $-\left(w_{S}-w_{L}\right)<0$. But then, increasing $r_{L}$ to $r_{L}^{\prime}=r_{S}-\left(w_{S}-w_{L}\right)+\varepsilon$ and reducing $r_{A}$ by the same amount (so as to keep $r_{A L}$ constant) would lead those consumers with $s<\tau^{\prime}=\varepsilon$ to buy $B_{S}$ from $S$, allowing $L$ to avoid granting them the subsidy $r_{L}$

It follows that there is no equilibrium such that $v_{A L}=v_{S}$.

Finally, loss leading (in which $L$ not only offers, but actually sells below cost) can only arise when $L$ sells to one-stop shoppers, which thus requires $v_{A L} \geq v_{S}$. But this cannot be an equilibrium when $w_{A L}<\hat{w}_{A L}\left(w_{S}, w_{L}\right)$, since: (i) in the range $v_{A L}>v_{S}$, the 
only such candidate is the above described loss-leading outcome, which requires $w_{A L} \geq$ $\hat{w}_{A L}\left(w_{S}, w_{L}\right)$; and (ii) as just discussed, no equilibrium exists in the boundary case $v_{A L}=$ $v_{S}$.

\section{Proof of Proposition 3}

Stackelberg leadership. Suppose that $L$ benefits from a first-mover advantage: it sets its prices first, and then, having observed these prices, $S$ sets its own price. Retail prices are often strategic complements, and it is indeed the case here for $S$ in the $B$ segment: as noted before, $S$ 's best response, $\hat{r}_{S}\left(r_{L}\right)$, increases with $r_{L}$. Thus, in the case of "normal competition" in market $B, L$ would exploit its first-mover advantage by increasing its price for $B_{L}$, so as to encourage its rival to increase its own price and relax the competitive pressure. In contrast, here $L$ has an incentive to decrease $r_{L}$ even further. This leads $S$ to decrease its own price, which allows $L$ to raise the price for $A$. To see this, note that $L$ 's Stackelberg profit from a loss-leading strategy can be written as:

$$
\Pi_{L}^{S}\left(r_{L}\right)=\Pi_{A L}^{m}-r_{L} F\left(\hat{\tau}\left(r_{L}\right)\right)=\Pi_{A L}^{m}-r_{L} F\left(w_{S}-w_{L}+r_{L}-\hat{r}_{S}\left(r_{L}\right)\right)
$$

Denoting by $r_{L}^{S}$ the optimal Stackelberg margin and using $\hat{r}_{S}\left(\hat{r}_{L}^{*}\right)=\hat{r}_{S}^{*}$, where $\hat{r}_{L}^{*}$ and $\hat{r}_{S}^{*}$ are the equilibrium margins when $L$ moves simultaneously with $S$, we have:

$$
\begin{aligned}
-r_{L}^{S} F\left(w_{S}-w_{L}+r_{L}^{S}-\hat{r}_{S}\left(r_{L}^{S}\right)\right) & \geq-\hat{r}_{L}^{*} F\left(w_{S}-w_{L}+\hat{r}_{L}^{*}-\hat{r}_{S}\left(\hat{r}_{L}^{*}\right)\right) \\
& \geq-r_{L}^{S} F\left(w_{S}-w_{L}+r_{L}^{S}-\hat{r}_{S}^{*}\right),
\end{aligned}
$$

where the second inequality stems from the fact that $\hat{r}_{L}^{*}$ constitutes $L$ 's best response to $r_{S}^{*}$. Since $-r_{L}^{S}>0$ and $F(\cdot)$ and $\hat{r}_{S}(\cdot)$ are both increasing, this in turn implies $r_{L}^{S} \leq \hat{r}_{L}^{*}$. This inequality is moreover strict, since (using $\left.\hat{\tau}\left(\hat{r}_{L}^{*}\right)=\hat{\tau}^{*}\right)$ :

$$
\left(\Pi_{L}^{S}\right)^{\prime}\left(\hat{r}_{L}^{*}\right)=-F\left(\hat{\tau}^{*}\right)-\hat{r}_{L}^{*} f\left(\hat{\tau}^{*}\right)\left(1-\hat{r}_{S}^{\prime}\left(\hat{r}_{L}^{*}\right)\right)=\hat{r}_{L}^{*} f\left(\hat{\tau}^{*}\right) \hat{r}_{S}^{\prime}\left(\hat{r}_{L}^{*}\right)<0 .
$$

Thus, $L$ sells the competitive product $B_{L}$ further below-cost, compared with what it would do in the absence of a first-mover advantage: $r_{L}^{S}<\hat{r}_{L}^{*}$.

Entry accommodation. Suppose now that the presence of $S$ is uncertain. To capture this possibility, assume that $S$ incurs a fixed cost for entering the market, $\gamma$, which is ex ante distributed according to a cumulative distribution function $F_{\gamma}(\cdot)$, and consider the following timing: 
- In stage $1, L$ chooses its prices.

- In stage 2 , the entry cost is realized, and $S$ chooses whether to enter; if it enters, it then sets its own price.

If entry were certain, maximizing its Stackelberg profit would lead $L$ to adopt $r_{L}^{S}$. But now, $S$ enters only when its best response profit, $\hat{\Pi}_{S}\left(r_{L}\right)$, exceeds the realized cost $\gamma$, which occurs with probability $\rho\left(r_{L}\right) \equiv F_{\gamma}\left(\hat{\Pi}_{S}\left(r_{L}\right)\right)$. L's ex ante profit is therefore equal to

$$
\hat{\Pi}_{L}^{S}\left(r_{L}\right)=\Pi_{A L}^{m}+\rho\left(r_{L}\right) \Pi_{L}^{S}\left(r_{L}\right)
$$

The optimal margin, $\hat{r}_{L}^{S}$, thus satisfies

$$
\rho\left(\hat{r}_{L}^{S}\right) \Pi_{L}^{S}\left(\hat{r}_{L}^{S}\right) \geq \rho\left(r_{L}^{S}\right) \Pi_{L}^{S}\left(r_{L}^{S}\right) \geq \rho\left(r_{L}^{S}\right) \Pi_{L}^{S}\left(\hat{r}_{L}^{S}\right)
$$

which implies

$$
\rho\left(\hat{r}_{L}^{S}\right) \geq \rho\left(r_{L}^{S}\right)
$$

Since $F_{\gamma}$ and $\hat{\Pi}_{S}$ are both increasing in $r_{L}$, so is $\rho$ and thus $\hat{r}_{L}^{S} \geq r_{L}^{S}$. This inequality is moreover strict, since

$$
\left(\hat{\Pi}_{L}^{S}\right)^{\prime}\left(r_{L}^{S}\right)=\rho^{\prime}\left(r_{L}^{S}\right) \Pi_{L}^{S}\left(r_{L}^{S}\right)+\rho\left(r_{L}^{S}\right)\left(\Pi_{L}^{S}\right)^{\prime}\left(r_{L}^{S}\right)=\rho^{\prime}\left(r_{L}^{S}\right) \Pi_{L}^{S}\left(r_{L}^{S}\right)>0 .
$$

Therefore, when L's comparative advantage leads it to adopt a loss-leading strategy, it limits the subsidy on $B$ so as to increase the likelihood of entry: $\hat{r}_{L}^{S}>r_{L}^{S}$.

\section{Proof of Proposition 4}

In the equilibrium where $L$ attracts one-stop shoppers in the absence of a ban, $L$ must offer a higher value than $S: v_{A L}=v_{A L}^{m}>\hat{v}_{S}^{*}=w_{S}-\hat{r}_{S}^{*}$, and $S$ must moreover not be tempted to deviate and attract one-stop shoppers, which boils down to $\hat{\Pi}_{S}^{*}=h\left(\hat{\tau}^{*}\right) F\left(\hat{\tau}^{*}\right) \geq$ $\hat{\Pi}_{S}^{d}=\left(w_{S}-v_{A L}^{m}\right) F\left(v_{A L}^{m}\right)$. If $L$ keeps attracting one-stop shoppers (i.e., $\left.v_{A L}>v_{S}\right)$ when loss leading is banned, then the unique candidate equilibrium is $r_{A L}=r_{A L}^{m}, r_{L}=0$ and $r_{S}^{b}=h\left(\tau^{*}\right)$, where $\tau^{*}=l^{-1}\left(w_{S}-w_{L}\right)$.

We show now this candidate equilibrium prevails when loss-leading would arise if below-cost pricing were allowed. Note that, since $S$ increases its price (i.e., $r_{S}^{b}=h\left(\tau^{*}\right)>$ $\left.\hat{r}_{S}^{*}=h\left(\hat{\tau}^{*}\right)\right)$, it offers less value $\left(v_{S}=v_{S}^{b} \equiv w_{S}-r_{S}^{b}<\hat{v}_{S}^{*}\right)$, and thus $L$ indeed attracts 
one-stop shoppers: $v_{A L}=v_{A L}^{m}>\left(\hat{v}_{S}^{*}>\right) v_{S}^{b}$. Furthermore, as $S$ must again offer at least $v_{S}=v_{A L}$ to attract one-stop shoppers, it still cannot obtain more than $\hat{\Pi}_{S}^{d}$ by deviating in this way. Therefore, since $S$ now obtains more profit $\left(\Pi_{S}^{*} \equiv h\left(\tau^{*}\right) F\left(\tau^{*}\right)>\hat{\Pi}_{S}^{*}=\right.$ $\left.h\left(\hat{\tau}^{*}\right) F\left(\hat{\tau}^{*}\right)\right)$, it is less tempted to deviate: $\Pi_{S}^{*}>\left(\hat{\Pi}_{S}^{*}>\right) \hat{\Pi}_{S}^{d}$. It follows that the conditions for sustaining the above equilibrium are less stringent than that for the loss-leading equilibrium.

\section{E Product differentiation in the competitive market}

We show that our main insights apply when consumers vary in their relative preferences over $B_{L}$ and $B_{S}$. For example, suppose $B_{L}$ is a "standard" variety generating a homogeneous utility $u_{L}$, whereas $B_{S}$, a better variety supplied by specialist stores, yields a utility $u_{S}+\theta q ; \theta \in[0,1]$ thus characterizes the consumer preference for quality and is distributed according to a c.d.f $\Phi(\cdot)$ with density function $\phi(\cdot)$, whereas $q$ measures the degree of consumer heterogeneity. For the sake of exposition, we consider here the case where $B_{S}$ is supplied by a competitive fringe and assume that:

- $S$ provides better value for at least some quality-oriented consumers: $w_{S}+q>w_{L}$; we allow however for $w_{L}>w_{S}$, in which case $L$ offers higher value than $S$ for less quality-oriented consumers.

- all one-stop shoppers favor $L: v_{A L} \geq w_{S}+q$.

As before, consumers are willing to patronize $L$ if $s \leq v_{A L}$, and prefer multi-stop shopping to one-stop shopping if

$$
s \leq w_{S}+\theta q-v_{L}=\tau+\theta q,
$$

where $\tau=w_{S}-w_{L}+r_{L} . L$ thus earns a profit

$$
\Pi_{L}=r_{A L} D_{A L}\left(r_{A L}\right)-r_{L} D_{A S}\left(r_{L}\right)
$$

where $D_{A L}\left(r_{A L}\right)=F\left(v_{A L}\right)$ and $D_{A S}\left(r_{L}\right)=\int_{0}^{1} F(\tau+\theta q) \phi(\theta) d \theta$. The loss leading logic of the baseline model applies again here: since $v_{A L}=w_{A L}-r_{A L}$ and $\tau=w_{S}-w_{L}+r_{L}, L$ 's profit is separable in $r_{A L}$ and $r_{L}$, and still charges the price on $B_{L}$ below-cost. 
While we presented this example in terms of "vertical" quality differentiation, the same analysis applies to "horizontal" differentiation, with utilities for $B_{L}$ and $B_{S}$ of the form $u_{L}+(1-\theta) q$ and $u_{S}+\theta q$; the only difference is that, since consumers have now heterogeneous valuations for $B_{L}$ as well, the above demands become:

$$
D_{A L}\left(r_{A L}\right)=\int_{0}^{1} F\left(v_{A L}+(1-\theta) q\right) \phi(\theta) d \theta, D_{A S}\left(r_{L}\right)=\int_{0}^{1} F(\tau+(2 \theta-1) q) \phi(\theta) d \theta .
$$

\section{F $\quad$ Proof of Proposition 6}

\section{F.1 Local Monopolies with heterogeneous preferences on $A$}

We show that introducing an elastic demand in market $A$ does not preclude the large retailer from adopting a loss-leading strategy, so as to extract additional surplus from multi-stop shoppers. We focus on the large retailer's best response to the strategies of the smaller retailer(s); thus, what follows applies equally to the case of a strategic rival and that of a competitive fringe.

$L$ 's profit can be written as (see Figure 1):

$$
\Pi_{L}=r_{A L} D_{A L}+r_{A} D_{A S}=r_{A L} \int_{\tau}^{v_{A L}} G\left(x_{A L}(s)\right) f(s) d s+r_{A} \int_{0}^{\tau} G\left(x_{A}(s)\right) f(s) d s .
$$

To characterize the equilibrium values of $r_{L}$ and $r_{A L}$, consider first a modification of $r_{A}$ by $d r$, adjusting $r_{L}$ by $-d r$ so as to keep $r_{A L}$ constant. Such a change does not affect the behavior of one-stop shoppers (it has no impact on $v_{A L}$ and $x_{A L}(s)$ ), but (see Figure 2):

- It affects multi-shop shoppers: for $s<\tau$, the marginal consumer indifferent between buying $A$ from $L$ or patronizing $S$ only becomes $x=x_{A}(s)-d r$; therefore, $L$ loses $g\left(x_{A}(s)\right) d r$ consumers, on which it no longer earns the margin $r_{A}$. $L$ however increases its margin by $d r$ on the mass $G\left(x_{A}(s)\right)$ of consumers that buy $A$. Thus, the overall impact of such an adjustment on multi-stop shoppers is equal to

$$
\int_{0}^{\tau}\left[G\left(x_{A}(s)\right)-r_{A} g\left(x_{A}(s)\right)\right] f(s) d s d r .
$$

- In addition, it alters the choice between one-stop and multi-stop shopping: those consumers for which $s \in[\tau-d r, \tau]$ and $x \leq x_{A}(s)$ turn to one-stop shopping and now buy $B$ as well as $A$ from $L_{1}$, which (noting that $x_{A}(\tau)=\hat{x}$ ) brings a gain $r_{L} G(\hat{x}) f(\tau) d r$. 
These effects must cancel out in equilibrium, which yields

$$
\int_{0}^{\tau}\left[r_{A}-k\left(x_{A}(s)\right)\right] g\left(x_{A}(s)\right) f(s) d s=r_{L} G(\hat{x}) f(\tau) .
$$

Likewise, adjusting slightly $r_{A L}$ by $d r$, keeping $r_{A}$ constant (and thus changing $r_{L}$ by $d r$ as well) does not affect the behavior of multi-stop shoppers (it has no impact on $v_{A S}$ and $\left.x_{A}(s)\right)$, but:

- It affects one-stop shoppers: for $s>\tau$, the marginal shopper becomes $x=x_{A L}(s)-$ $d r$, and the resulting change in profit is

$$
\int_{\tau}^{v_{A L}}\left[G\left(x_{A L}(s)\right)-r_{A L} g\left(x_{A L}(s)\right)\right] f(s) d s d r .
$$

- In addition, those consumers for which $s \in[\tau, \tau+d r]$ and $x \leq x_{A L}(s)$ become multi-stop shoppers and stop buying $B$ from $L$, which (noting that $x_{A L}(\tau)=\hat{x}$ ) brings a net effect $-r_{L} G(\hat{x}) f(\tau) d r$.

In equilibrium, these effects must again cancel each other, which yields

$$
\int_{\tau}^{v_{A L}}\left[r_{A L}-k\left(x_{A L}(s)\right)\right] g\left(x_{A L}(s)\right) f(s) d s=-r_{L} G(\hat{x}) f(\tau) .
$$

Therefore, if in equilibrium $r_{L}$ were non-negative, we would have

$$
\int_{0}^{\tau}\left[r_{A}-k\left(x_{A}(s)\right)\right] g\left(x_{A}(s)\right) f(s) d s \geq 0 \geq \int_{\tau}^{v_{A L}}\left[r_{A L}-k\left(x_{A L}(s)\right)\right] g\left(x_{A L}(s)\right) f(s) d s,
$$

that is, $r_{A}$ would exceed a weighted average of $k\left(x_{A}(s)\right)$ for $s \in[0, \tau]$, whereas $r_{A L}$ would be lower than a weighted average of $k\left(x_{A L}(s)\right)$ for $s \in\left[\tau, v_{A L}\right]$. But since $k\left(x_{A}(s)\right)$ and $k\left(x_{A L}(s)\right)$ decrease as $s$ increases $\left(k(\right.$.$) increases by assumption, and both x_{A}(s)$ and $x_{A L}(s)$ decrease by construction), this would imply $r_{A}>r_{A L}$, a contradiction. Therefore, in equilibrium, $r_{L}<0$.

If the shopping cost $s$ is distributed over some interval $[0, \bar{s}]$, where $\bar{s}>\tau$ to ensure that large retailers still attract some one-stop shoppers, the first-order conditions become:

$$
\begin{aligned}
\int_{0}^{\tau}\left[r_{A}-k\left(x_{A}(s)\right)\right] g\left(x_{A}(s)\right) f(s) d s & =r_{L} G(\hat{x}) f(\tau) \\
\int_{\tau}^{\min \left\{v_{A L}, \bar{s}\right\}}\left[r_{A L}-k\left(x_{A L}(s)\right)\right] g\left(x_{A L}(s)\right) f(s) d s & =-r_{L} G(\hat{x}) f(\tau)
\end{aligned}
$$

it thus suffices to replace $v_{A L}$ with $\min \left\{v_{A L}, \bar{s}\right\}$ in the above reasoning. 


\section{F.2 Imperfect competition among large retailers}

Suppose now that two large retailers, $L_{1}$ and $L_{2}$, facing the same costs in both markets and offering the same variety $B_{L}$, are differentiated in market $A$ : they respectively offer $A_{1}$ and $A_{2}$, located at the two ends of a Hotelling line of length $X$; a consumer with preference $x$ thus obtains a utility $u_{A}-x-p_{A_{1}}=w_{A}-r_{A_{1}}-x$ from buying $A_{1}$ and a utility $w_{A}-r_{A_{2}}-(X-x)$ from buying $A_{2}$. We will restrict attention to symmetric distributions (that is, the density $g(\cdot)$ satisfies $g(x)=g(X-x)$ ) and will focus on (symmetric) equilibria in which: (i) the large retailers compete against each other as well as against their smaller rivals; (ii) small retailers attract some multi-stop shoppers by offering a value $v_{S}$ that exceeds the value $v_{L}$ offered by large retailers on the $B$ market; and (iii) large retailers attract some one-stop shoppers by offering them a value $v_{A L}$ that exceeds $v_{S}$, as well as the value $v_{A}$ that they offer on the $A$ market alone.

Large retailers may compete against each other for one-stop and/or for multi-stop shoppers. In the former case, in a symmetric equilibrium (of the form $r_{A_{1} L_{1}}=r_{A_{2} L_{2}}=r_{A L}$ and $r_{L_{1}}=r_{L_{2}}=r_{L}$ ) some consumers (with $x=X / 2$ ) are indifferent between buying both goods from either $L_{1}$ or $L_{2}$, and prefer doing so to patronizing $S$ only; this implies (using $x=X / 2$, and dropping the subscripts 1 and 2 for ease of exposition):

$$
\hat{v}_{A L} \equiv v_{A L}-\frac{X}{2} \geq v_{S}
$$

which is equivalent to

$$
\hat{v}_{A} \equiv v_{A}-\frac{X}{2} \geq \tau=v_{S}-v_{L}
$$

Therefore, consumers with preference $x=X / 2$ and shopping cost $s<\tau$, who thus prefer multi-stop shopping (that is, buying $B_{S}$ from $S$ and $A$ from either $L_{1}$ or $L_{2}$ ) to visiting $L_{1}$ or $L_{2}$ only, also prefer multi-stop shopping to patronizing $S$ only (since $s<\tau$ then implies $s<\hat{v}_{A}$ ). In other words, if large retailers compete for one-stop shoppers, they will also compete for multi-stop shoppers. This observation allows us to classify the (symmetric) candidate equilibria into two types:

- Type $M$ : large retailers compete only for multi-stop shoppers (see Figure 3a);

- Type O: large retailers compete for one-stop shoppers as well as for multi-stop shoppers (see Figure 3b). 


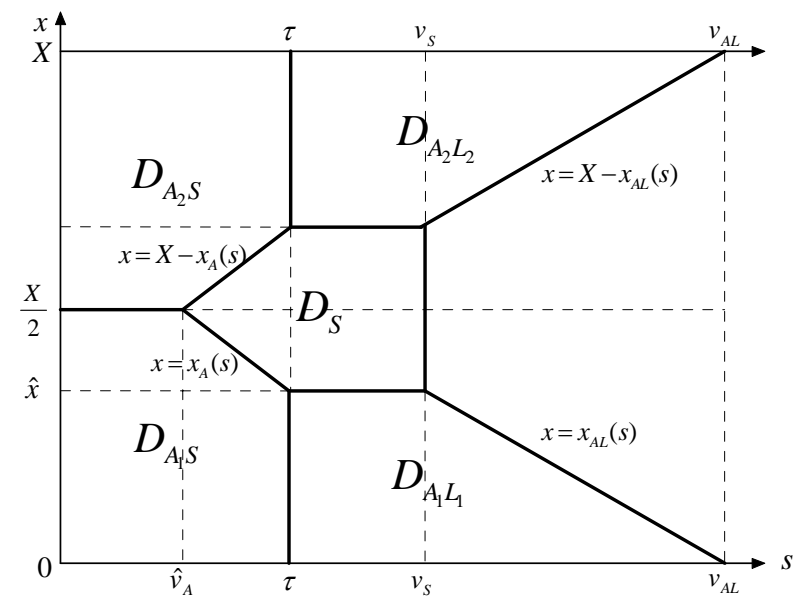

Figure $3 \mathrm{a}$

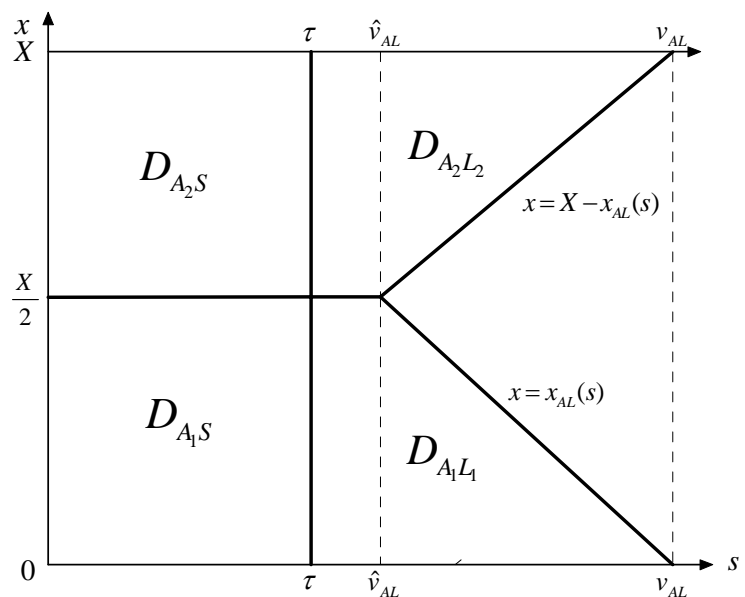

Figure $3 b$

In the first type of equilibria (Figure 3a), for $x=X / 2$ some consumers with low shopping costs are indifferent between assortments $A_{1} S$ and $A_{2} S$, and prefer those assortments to any other option, whereas consumers with higher shopping costs patronize $S$ only; the relevant threshold for the shopping cost satisfies

$$
\hat{v}_{A}+v_{S}-2 s=v_{S}-s
$$

that is, $s=\hat{v}_{A}$. Consumers with $s<\hat{v}_{A}$ thus buy $B$ from $S$ and $A$ from either $L_{1}$ or $L_{2}$ (depending on whether $x$ is smaller or larger than $X / 2$ ). Conversely, consumers whose shopping costs exceed $v_{A L}$ do not shop. As for consumers whose shopping costs lie between $\hat{v}_{A}$ and $v_{A L}$ :

- when $s<\tau$, consumers still buy $B_{S}$ from $S$; they also buy $A$ from $L_{1}$ if $x<x_{A}(s)=$ $v_{A}-s$, or from $L_{2}$ if $x>X-x_{A}(s)$;

- when $s>\tau$ :

- if $x<x_{A L}(s)$, consumers buy both goods from $L_{1}$;

- if $x>X-x_{A L}(s)$, consumers buy both goods from $L_{2}$;

- if $x_{A L}(s)<x<X-x_{A L}(s)$, consumers patronize $S$ if $s<v_{S}$, and buy nothing otherwise.

In the second type of equilibria (Figure 3b), all consumers with a shopping cost $s<\tau$ buy $B_{S}$ from $S$ and $A$ from either $L_{1}$ (if $x<X / 2$ ) or $L_{2}$ (if $x>X / 2$ ), while consumers with $s>v_{A L}$ buy nothing. For consumers with $\tau<s<v_{A L}$, then: 
- if $s<\hat{v}_{A L}$, consumers will buy both goods from either $L_{1}$ (if $x<X / 2$ ) or $L_{2}$ (if $x>X / 2)$;

- if $\hat{v}_{A L}<s<v_{A L}$, consumers will buy both goods from $L_{1}$ if $x<x_{A L}(s)$ or from $L_{2}$ if $x>X-x_{A L}(s)$, and buy nothing otherwise.

A similar description applies when the shopping cost $s$ is bounded, truncating as necessary the interval for $s$.

We show now loss leading is still used as an exploitative device. Consider first (symmetric) equilibria of type $M$, in which large retailers compete only for multi-stop shoppers. In the absence of any bound on shopping costs, the demands for assortments $A_{1} L_{1}$ and $A_{1} S$ in such equilibrium, where $r_{A_{1} L_{1}}=r_{A_{2} L_{2}}=r_{A L}$ and $r_{L_{1}}=r_{L_{2}}=r_{L}$ (and thus $r_{A_{1}}=r_{A_{2}}=r_{A}$ ), can be expressed as:

$$
D_{A S}=\int_{0}^{\tau} G\left(\hat{x}_{A}(s)\right) f(s) d s \text { and } D_{A L}=\int_{\tau}^{v_{A L}} G\left(x_{A L}(s)\right) f(s) d s,
$$

where as before $\tau=v_{S}-v_{L}$ and $x_{A L}(s)=v_{A L}-\max \left\{s, v_{S}\right\}$, and $\hat{x}_{A}(s) \equiv v_{A}-\max \left\{s, \hat{v}_{A}\right\}$ $=\min \left\{X / 2, x_{A}(s)=v_{A}-s\right\}$.

Applying the same approach as above, starting from a candidate symmetric equilibrium, consider first a small change $d r$ in $r_{A_{1}}$, adjusting $r_{L_{1}}$ by $-d r$ so as to keep $r_{A_{1} L_{1}}$ constant:

- For $s<\hat{v}_{A}$, the marginal consumer who is indifferent between buying $A$ from $L_{1}$ or $L_{2}$ is such that:

$$
w_{A}-\left(r_{A}+d r\right)-x=w_{A}-r_{A}-(X-x),
$$

or:

$$
x=\frac{X}{2}-\frac{d r}{2}
$$

The overall impact on $L_{1}$ 's profit is thus:

$$
\int_{0}^{\hat{v}_{A}}\left[G\left(\hat{x}_{A}(s)\right)-\frac{1}{2} r_{A} g\left(\hat{x}_{A}(s)\right)\right] f(s) d s d r .
$$

- For $\hat{v}_{A}<s<\tau$, the marginal consumer indifferent between buying $A$ from $L_{1}$ or patronizing $S$ becomes $x=x_{A}(s)-d r$, and the resulting impact on profit is:

$$
\int_{\hat{v}_{A}}^{\tau}\left[G\left(\hat{x}_{A}(s)\right)-r_{A} g\left(\hat{x}_{A}(s)\right)\right] f(s) d s d r .
$$


- In addition, those consumers for which $s \in[\tau-d r, \tau]$ and $x \leq \hat{x}_{A}(s)$ turn to onestop shopping and now buy $B$ as well as $A$ from $L_{1}$, which brings an additional profit $r_{L} G(\hat{x}) f(\tau) d r$.

Therefore, in equilibrium, we must have:

$$
\int_{0}^{\tau}\left[r_{A}-\eta_{A}(s)\right] \hat{g}\left(\hat{x}_{A}(s)\right) f(s) d s=r_{L} G(\hat{x}) f(\tau),
$$

where (using $\hat{x}_{A}(s)=X / 2$ for $\left.s \leq \hat{v}_{A}\right)$ :

$$
\eta_{A}(s) \equiv\left\{\begin{array} { c } 
{ 2 k ( \hat { x } _ { A } ( s ) ) \text { for } s < \hat { v } _ { A } } \\
{ k ( \hat { x } _ { A } ( s ) ) \text { for } s > \hat { v } _ { A } }
\end{array} \text { and } \hat { g } ( x ) \equiv \left\{\begin{array}{c}
\frac{g(X / 2)}{2} \text { for } x=X / 2 \\
g(x) \text { for } x<X / 2
\end{array}\right.\right.
$$

Consider now a small change $d r$ in $r_{A_{1} L_{1}}$, keeping $r_{A_{1}}$ constant (and thus adjusting $r_{L_{1}}$ by $d r$ as well):

- for $s>\tau$, the marginal (one-stop) shopper becomes $x=x_{A L}(s)-d r$ and the impact on the profit is

$$
\int_{\tau}^{v_{A L}}\left[G\left(x_{A L}(s)\right)-r_{A L} g\left(x_{A L}(s)\right)\right] f(s) d s d r
$$

- in addition, those consumers for which $s \in[\tau, \tau+d r]$ and $x \leq x_{A L}(s)$ become multistop shoppers and stop buying $B$ from $L_{1}$, which brings a net loss $-r_{L} G(\hat{x}) f(\tau) d r$.

In equilibrium, we must therefore have

$$
\int_{\tau}^{v_{A L}}\left[r_{A L}-\eta_{A L}(s)\right] g\left(x_{A L}(s)\right) f(s) d s=-r_{L} G(\hat{x}) f(\tau)
$$

where $\eta_{A L}(s) \equiv k\left(x_{A L}(s)\right)$.

Thus, if $r_{L}$ were non-negative, the two conditions (14) and (15) would imply

$$
\int_{0}^{\tau}\left[r_{A}-\eta_{A}(s)\right] \hat{g}\left(\hat{x}_{A}(s)\right) f(s) d s \geq 0 \geq \int_{\tau}^{v_{A L}}\left[r_{A L}-\eta_{A L}(s)\right] g\left(x_{A L}(s)\right) f(s) d s,
$$

where $\eta_{A}$ and $\eta_{A L}$ decrease as $s$ increases, and coincide for $s=\tau$; this, in turn, would imply $r_{A}>r_{A L}$, a contradiction. A similar argument applies when the shopping cost $s$ is distributed over some interval $[0, \bar{s}]$.

The same approach can be used for (symmetric) equilibria of type $O$, in which large retailers compete as well for one-stop shoppers. In the absence of any bound on shopping 
costs, the demands for assortments $A_{1} L_{1}$ and $A_{1} S$ in such equilibrium can be expressed as

$$
D_{A S}=\int_{0}^{\tau} G\left(\frac{X}{2}\right) f(s) d s \text { and } D_{A L}=\int_{\tau}^{v_{A L}} G\left(\hat{x}_{A L}(s)\right) f(s) d s,
$$

where $\hat{x}_{A L}(s) \equiv v_{A}-\max \left\{s, \hat{v}_{A L}\right\}=\min \left\{X / 2, x_{A L}(s)=v_{A L}-s\right\}$.

Following a small change $d r$ in $r_{A_{1}}$, adjusting $r_{L_{1}}$ by $-d r$ so as to keep $r_{A_{1} L_{1}}$ constant, we have:

- for $s<\tau$, the marginal consumer indifferent between buying $A$ from $L_{1}$ or $L_{2}$ becomes $X / 2-d r / 2$;

- in addition, those consumers for which $s \in[\tau-d r, \tau]$ and $x \leq \hat{x}_{A}(s)$ become onestop shoppers.

Therefore, in equilibrium we must have

$$
\int_{0}^{\tau}\left[r_{A}-\hat{\eta}_{A}\right] \hat{g}\left(\frac{X}{2}\right) f(s) d s=r_{L} G\left(\frac{X}{2}\right) f(\tau),
$$

where $\hat{\eta}_{A} \equiv 2 k(X / 2)$ and $\hat{g}(X / 2)=g(X / 2) / 2$.

Likewise, following a small change $d r$ in $r_{A_{1} L_{1}}$, keeping $r_{A_{1}}$ constant (and thus changing $r_{L_{1}}$ by $d r$ as well), we have:

- for $\tau<s<\hat{v}_{A L}$, the marginal (one-stop) shopper becomes $x=x_{A L}(s)-d r / 2$;

- for $\hat{v}_{A L}<s<v_{A L}$, the marginal (one-stop) shopper becomes $x=x_{A L}(s)-d r$;

- in addition, those consumers for which $s \in[\tau, \tau+d r]$ and $x \leq \hat{x}_{A L}(s)$ become multi-stop shoppers: they stop buying $B$ from $L_{1}$.

We must therefore have

$$
\int_{\tau}^{v_{A L}}\left[r_{A L}-\hat{\eta}_{A L}(s)\right] \hat{g}\left(\hat{x}_{A L}(s)\right) f(s) d s=-r_{L} G(\hat{x}) f(\tau),
$$

where

$$
\hat{\eta}_{A L}(s) \equiv\left\{\begin{array}{c}
2 k\left(\hat{x}_{A L}(s)\right) \text { for } s<\hat{v}_{A L} \\
k\left(\hat{x}_{A L}(s)\right) \text { for } s>\hat{v}_{A L}
\end{array},\right.
$$

and $\hat{g}(x)$ is defined above with $\hat{x}_{A L}(s)=X / 2$ for $\tau \leq s \leq \hat{v}_{A L}$. Thus, if $r_{L}$ were non-negative, the above two conditions would imply:

$$
\int_{0}^{\tau}\left[r_{A}-\hat{\eta}_{A}\right] \hat{g}\left(\frac{X}{2}\right) f(s) d s \geq 0 \geq \int_{\tau}^{v_{A L}}\left[r_{A L}-\hat{\eta}_{A L}(s)\right] \hat{g}\left(\hat{x}_{A L}(s)\right) f(s) d s,
$$


and a contradiction follows, since $\hat{x}_{A L}(s) \leq X / 2$, with a strict inequality for $s>\hat{v}_{A L}$, and thus $\hat{\eta}_{A L}(s) \leq 2 k\left(\hat{x}_{A L}(s)\right) \leq \hat{\eta}_{A}$, with again a strict inequality for $s>\hat{v}_{A L}$. A similar argument applies again when the shopping cost $s$ is distributed over some interval $[0, \bar{s}]$. If instead $\bar{s}<\hat{v}_{A L}$, then all consumers buy both goods, in which case $\hat{\eta}_{A L}()=.\hat{\eta}_{A}$ and $\hat{g}\left(\hat{x}_{A L}(s)\right)=\hat{g}(X / 2)$, and $r_{L}=0$. 